PROTOCOLO

Autoinforme

de adolescentes

ADA

Manual de aplicación,

corrección e interpretación

Lilian R. Daset

María Eugenia Fernández

C. Daniel Costa-Ball

Nina Peirano

Leandro Castelluccio

Concepción López Soler 


\section{AUTOINFORME DE ADOLESCENTES ADA}

Manual de aplicación, corrección e interpretación

Prof. Tit. Dra. Lilian R. Daset

Prof. Adj. Dra. María Eugenia Fernández

Prof.Adj. Mag. C. Daniel Costa-Ball

Lic. Nina Peirano

Mag. Leandro Castelluccio

Prof. Tit. Dra. Concepción López Soler

@)UCU 
Autoinforme de adolescentes (ADA) : Manual de aplicación, corrección e

interpretación / Lilian R. Daset ...[et al.], autores. - Montevideo : Universidad Católica del Uruguay ; 2021.

$113 \mathrm{p}$.

ISBN $978-991$

1.Psicopatolgía 2.Adolescencia 3.Evaluación psicológica 4.Bienestar psicológico 5.Variables sociodemográficas I. Título. II. Daset, Lilian, III.
Fernández, Ma. Eugenia, IV. Costa-Ball, C. Daniel, V. Peirano, Nina,

VI. Castelluccio, Leandro, VII. López Soler, Concepción.

CDD 155.5

Corrección de estilo: Mag. Elisa Valerio

Diseño y maquetación editorial: Leandro Stavorengo

Ilustración de portada: Leandro Stavorengo

Coordinación editorial: Prof. Dra. Lilian R. Daset

Libro de sello UCU

Impresión Mastergraf, Montevideo, Uruguay.

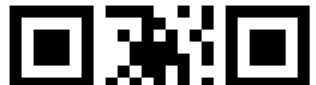 \\ 的 \\ (1) \\ 龊}

Cómo citar esta obra:

Daset, L. R., Fernández, M. E., Costa-Ball, C. D., Peirano, N., Castelluccio, L.

\& López Soler, C. (2021). Autoinforme de Adolescentes (ADA): Manual de aplicación,

corrección e interpretación. Montevideo: Universidad Católica del Uruguay. doi:

https://doi.org/10.22235/ada2021 
Tabla de contenidos

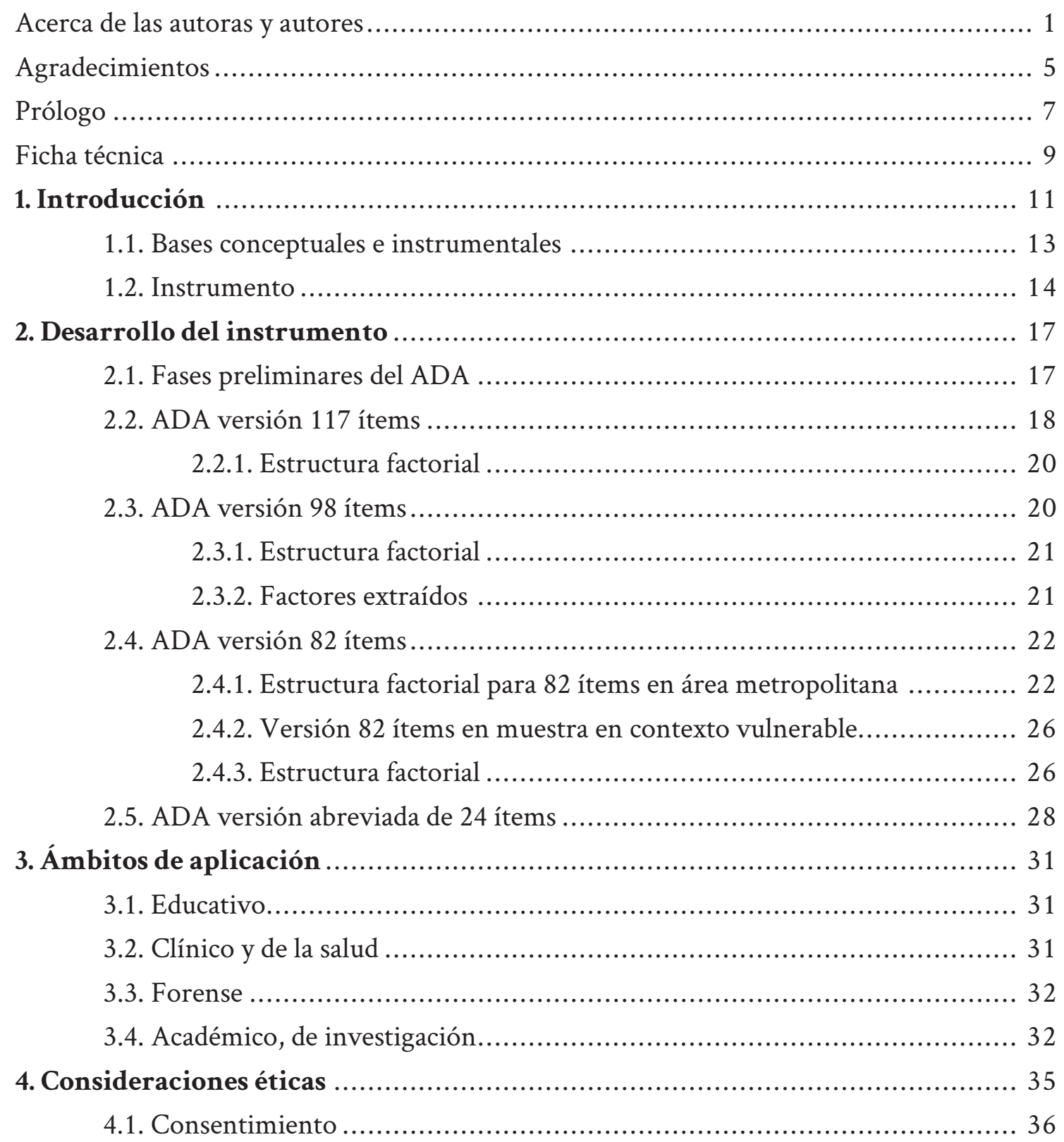


5. Administración del protocolo ADA

5.1. Normas de aplicación y corrección

5.1.1. Versión en papel......

5.1.2. Versión electrónica............................................................ 41

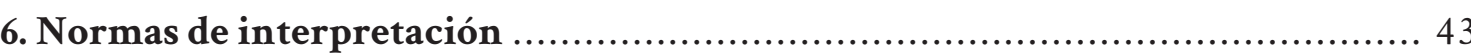

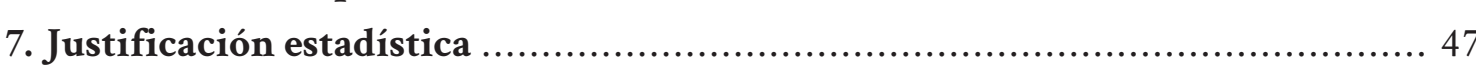

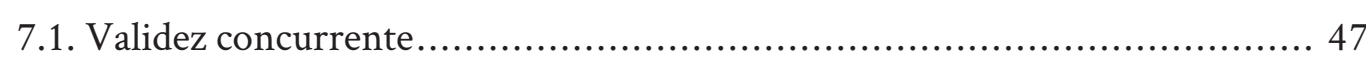

7.2. Correlaciones entre síndromes del ADA y otras técnicas .......................... 48

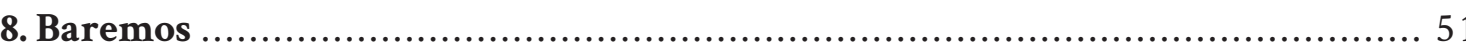

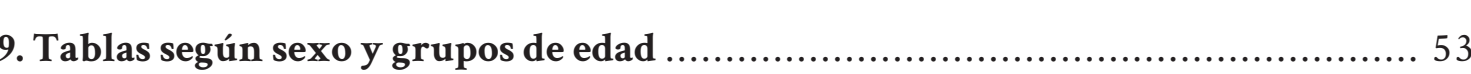

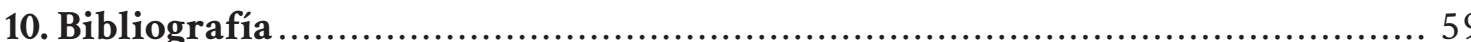

Anexos

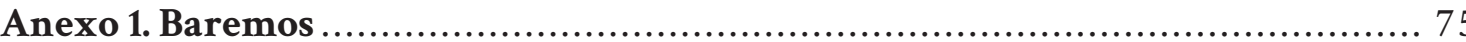

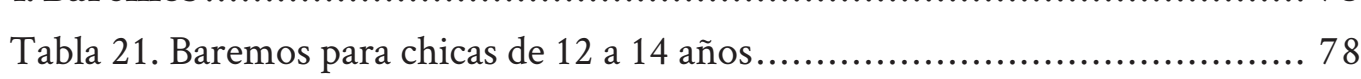

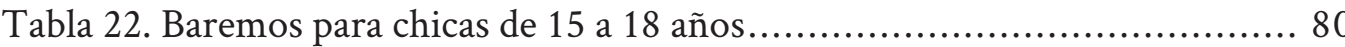

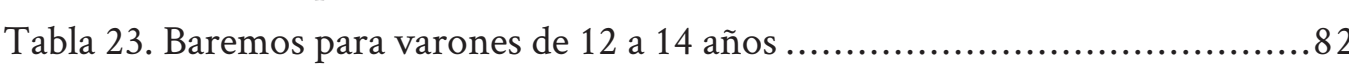

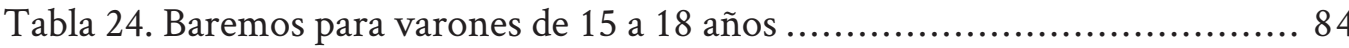

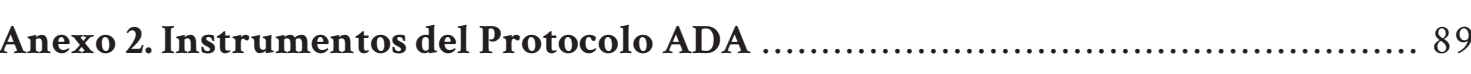

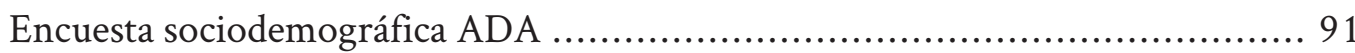

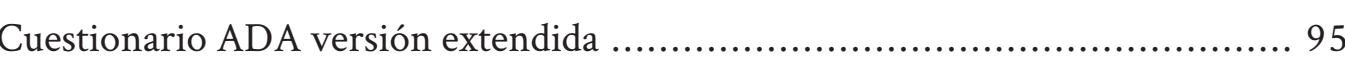

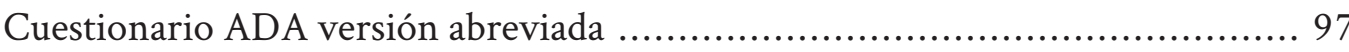

Anexo 3. Consentimiento informado ........................................................ 99 


\section{Acerca de las autoras y autores}

Lilian R. Daset Carretto: Doctora en Psicología con énfasis en Intervención Psicosocial por la Universidad de Murcia, España. Investigadora del Departamento de Psicología, responsable de la Línea de Investigación en Infancia y Adolescencia y del proyecto en Bienestar Psicológico. Profesora Titular grado 5 en programas de grado, maestría y doctorado de la Facultad de Ciencias de la Salud de la Universidad Católica del Uruguay, en la Facultad de Psicología de la Universidad de Buenos Aires; profesora invitada en maestrías y postgrados en distintas universidades y directora de tesis de doctorado, maestría y grado en psicología. Integrante del Sistema Nacional de Investigadores. Responsable de Publicaciones de la Universidad Católica del Uruguay. Integrante de Comités Editoriales de revistas científicas en psicología, de tribunales de concurso y evaluadora de proyectos de investigación y desarrollo a nivel nacional e internacional.

Maria Eugenia Fernández Pintos: Doctora en Psicología, Universidad Católica del Uruguay y Doctora en Ciencias de la Educación, Universidad de Gante, Bélgica. Magíster en Estudios Psicoanalíticos, Universidad de Essex, Reino Unido. Diplomada en Psicoterapia Grupal en comunidades terapéuticas, Universidad de Middlesex, Reino Unido. Investigadora del Departamento de Psicología y docente en Facultad de Ciencias de la Salud, Universidad Católica del Uruguay. Integrante del Sistema Nacional de Investigadores. Psicoterapeuta de niños y adolescentes en el ámbito privado y en el Sistema Nacional Integrado de Salud.

C. Daniel Costa-Ball: Magíster en Metodología de las Ciencias del Comportamiento y de la Salud por la Universidad Autónoma de Madrid, España; Experto en Diseño y Tratamiento Estadístico de Encuestas para Estudios de Mercado y Sondeo de Opinión por la Universidad Nacional de Educación a Distancia (UNED); Magíster en Psicología Educacional y Licenciado en Psicología por la Universidad Católica del Uruguay. Académico en el Departamento de Neurociencia y Aprendizaje, con publicaciones y proyectos de desarrollo de diseños de investigación, estudios metodológicos y análisis de datos. 
Nina Peirano: Licenciada en Psicología y postgraduada en Psicoterapia Integrativa Psiconeuroinmunoendócrina (PNIE) por la Universidad Católica del Uruguay. Estudios en Psicopedagogía en la Universidad de El Salvador. Psicoterapeuta miembro de la Federación Uruguaya de Psicoterapia (Fupsi) y la Asociación Latinoamericana de Psicoterapia Integrativa (Alapsi), y en servicios de la salud por la Universidad de la República. Asistente de investigación en Línea de Investigación de la Niñez y la Adolescencia y en Bienestar Psicológico del Departamento de Psicología de la Universidad Católica del Uruguay.

Leandro Castelluccio: Licenciado en Psicología por la Universidad Católica del Uruguay y Magíster en Neurociencia Cognitiva por la Universidad de Sussex, Reino Unido. Cofundador y presidente de Naxon Labs, empresa desarrolladora de tecnología EEG portátil en neurociencia y psicología. Estudios en modelos de análisis multivariados avanzados y en data science, desde los que se integra como investigador a la Línea de Investigación en Niñez y Adolescencia y al proyecto de Bienestar Psicológico del Departamento de Psicología de la Universidad Católica del Uruguay.

Concepción López Soler: Doctora en Psicología. Especialista en Psicología Clínica, Profesora Titular en la Universidad de Murcia, España. Vinculada clínica al servicio de pediatría del Hospital V. Arrixaca y responsable de la Unidad de Psicología Clínica de la Infancia y Adolescencia. Lidera el Grupo Universitario de Investigación en Infancia y Adolescencia, Psicología Clínica y los proyectos de Evaluación Diagnóstica y Tratamiento de Menores Tutelados y en aplicación de TIC’s (Realidad Virtual) a terapias de integración en menores maltratados. Participa de 7 equipos de investigación en proyectos de I+D+i competitivos en el área de la minoridad, el trauma complejo, la evaluación y diagnóstico, la intervención psicológica y las incidencias en la salud y la clínica. Autora de múltiples artículos, directora de tesis doctorales y conferencista internacional. 


\section{Agradecimientos}

Este manual ha sido posible gracias al apoyo de investigadores, estudiantes y colegas que, a lo largo de estos casi 20 años, han trabajado en la Línea de Investigación en Infancia y Adolescencia y con sus aportes han permitido construir las bases de desarrollo instrumental que aquí se presentan como producto de investigación en el Autoinforme de Adolescentes (ADA). Agradecemos a las magísteres Laura Ceria y Viviana Valdéz, a las licenciadas Andrea Arotce, María Benedetti, Paola Ceraolo, Yhara Cuitiño, Eugenia Díaz, Cecilia Larrieu, Ana López, Natalia Penas, Florencia Rivero, Silvia Rovegno, Margarita Suero, el licenciado Francisco Gil y las estudiantes Aline Dupré, Sofía Pizzarossa, Malena Sancristobal y Maia Yoffe de la Universidad Católica del Uruguay, y a las maestrandas en stagio de investigación en la Línea, Marieke Lambert y Lobke Volkaert de la Universidad de Gante, Bélgica.

Un especial lugar a los jueces expertos que con sus consideraciones y análisis crítico posibilitaron la concreción de este proyecto, de Uruguay, España y Argentina.

Este instrumento también ha transcurrido en varios escenarios, en la medida en que nos encontrábamos con expertos y coautores, quienes han acompañado con su alta calidad académica y experticia todo el proceso, en espacios tan variados como Montevideo, Murcia, Madrid, Oviedo, París y Buenos Aires, a lo que se sumó en los últimos años el Prof. Wouter Vanderplasschen y su equipo de investigación de la Universidad de Gante. Cada ocasión, en Uruguay o en cualquier otro lugar, era buena para trabajar en el instrumento, discutir las bases conceptuales, analizar resultados y avanzar.

A nuestras familias, que han tenido paciencia y nos han dado aliento; a los colegas de psicología de la Universidad Católica del Uruguay y a la Universidad toda, porque han dado soporte y toda clase de apoyos para que esto fuera posible, son tareas que se asumen desde un colectivo académico y por eso dan frutos; y a la Agencia Nacional de Investigación e Innovación por haber considerado este proyecto como viable en nuestras presentaciones como investigadores del sistema. 


\section{Prólogo}

Es conocida la idea de Wordsworth (1770-1850) de que el niño es el padre del hombre, frase que se convierte en sentencia si a ese niño y a ese adolescente no se lo considera más allá de las fronteras delineadas por las creencias imperantes histórica, social y familiarmente. Ese es, en ciernes, el adulto que devendrá por cada vez más años, según el aumento de la expectativa de vida, por tanto, toda acción que emprendamos para procurar esclarecer e intervenir en etapas tempranas, supone una apuesta fuerte a descender sus problemas en salud mental, sus conflictos familiares y sociales, los costes que de ellos devienen y por, sobre todo, aumentar sus posibilidades de bienestar para tanto tiempo por vivir.

Cuando comenzamos a trabajar hace años en el ámbito de la clínica con niños y adolescentes y posteriormente con adultos, fuimos viendo con claridad cómo esa frase de Wordsworth se iba dibujando en la vida de las personas que atendíamos, tomando forma de tristeza hasta llegar a la desesperanza, miedo tan atrapante que impedía tanto y le abroquelaba tras múltiples corazas y defensas, ansiedad que lo volvían desdichado, ira que lo hacían cometer actos violentos aún con los que aseguraba amar, desajuste y falta de adaptación porque pensaba tan diferente y así sentía y no entendía y no se entendía. Recorrimos varios trechos del camino junto a esas y otras formas de sufrimiento psíquico y eso nos impulsó a buscar estrategias de evaluación más rápidas y eficientes, a indagar sobre cómo la ciencia explicaba lo que ocurría y en tanto seguir intentando atisbar alguna luz que ayude a quien padece y al profesional que le atiende. Así nace este desarrollo instrumental, en habla hispana, al sur de las Américas, con el apoyo de mucha gente y con el expertís que nos proveyó el equipo de investigación de la Prof. López Soler en la Universidad de Murcia y la generosidad académica que distingue a muchos de nuestros colegas.

En una imperdible entrevista realizada a Sir Michel Rutter en 2008 en la Universidad de Oxford por los profesores Tansey e Iversen, recorriendo su historia académica y su trabajo en la isla de Wight, su reconocidísimo aporte al esclarecimiento de los trastornos del espectro autista, nos muestra una de sus fortalezas cuando dice que en ciencia se necesita 
cuestionar los propios hallazgos "despiadadamente", preguntándose reiteradamente sobre la evidencia y las formas de encontrarla, sin dejar de hacer lugar para lo inesperado.

Este desarrollo instrumental sigue esas premisas de Rutter y así se fueron edificando las bases conceptuales, buscando evidencias que pudiéramos transformar en reactivos, en esa encrucijada, de la que habla Rutter, entre lo psicosocial, lo biológico, lo clínico y la investigación académica, atendiendo a lo posible, creando un espacio para lo impensado, y al final contar con una forma de indagar sobre el sufrimiento psíquico de los adolescentes y también sobre su resiliencia y bienestar. Fue un camino largo, de muchas idas y vueltas, pero donde aprendimos tanto y de tantas personas, en especial de los jóvenes que, con esa franca generosidad que les caracteriza, nos hicieron partícipes de su mirada y sus confidencias. Mayor y mejor razón es difícil de encontrar.

\section{Lilian R. Daset \\ Lilian R. Daset}

\section{Nombre:}

Autores:

Procedencia:

Aplicación:

Ámbito de aplicación:

Tiempo de aplicación:

Finalidad:

Versiones:

Modalidades de aplicación:

Material necesario:

\section{Ficha técnica}

Autoinforme de Adolescentes (ADA)

R. Daset, María Eugenia Fernández, C. Daniel Costa-Ball, Nina Peirano, Leandro Castelluccio y Concepción López Soler

Montevideo, Uruguay

Individual y colectiva

Educativo y clínico

40 minutos promedio

Evaluar síndromes psicopatológicos y factores de protección y positivos en adolescentes de 12 a 18 años

Original (larga) y reducida

Manual y electrónico

1. Protocolo en papel, autocorregible, lápiz y goma

2. Encuesta electrónica, un dispositivo electrónico con conexión a internet 


\section{Introducción}

El instrumento de Autoinforme de Adolescentes (ADA) se inscribe en uno de los proyectos desarrollados en la Línea de Investigación en Niñez y Adolescencia (LINA) del Departamento de Psicología de la Universidad Católica del Uruguay. La línea fue fundada en el año 1998 y ha tenido como cometido el estudio de estas etapas evolutivas desde tres ángulos: el psicopatológico, el de las variables sociodemográficas y el de la prosocialidad, buscando y discriminando sobre el conjunto de reactivos que - posteriormente- han sido analizados, evaluados y reformulados con estudios comparativos y trabajos de campo.

El objetivo desde el inicio ha estado enmarcado en la necesidad de contar con información sobre el sufrimiento psíquico de los jóvenes, los ejes sociodemográficos en que se desarrollan, si hay algunos factores de protección y cómo están compuestos, conocer más sobre el interjuego que acontece entre ellos y atisbar algunas conclusiones, en una etapa evolutiva tan desafiante y de rápidos cambios. Como plantea Achenbach (2020) queda mucho por aprender sobre la naturaleza, etiología, curso y tratamientos apropiados, pero un diagnóstico a tiempo y con economía de recursos - por tanto, más factible de ser utilizado- puede colaborar en determinar la ayuda que esa persona en concreto necesita.

En los últimos diez años se sumaron aspectos positivos, resilientes y de bienestar, profundizando la mirada hacia los factores de protección y los que parecen ser su contrapartida, los de riesgo y vulnerabilidad, buscando conocer si ante la presencia de unos los otros se desarrollan y activan. Esto se ha visto plasmado en tesis de grado, postgrado, doctorales y en investigaciones que contienen estudios transculturales, lo que posibilita un desarrollo académico en torno a un tema de relevancia social, en esta franja etaria donde se necesita seguir construyendo saberes que aporten a las buenas prácticas.

Para alcanzar los objetivos propuestos, se ha desarrollado un instrumento de evaluación que atienda a los aspectos señalados. Cada vez se vuelve más imperioso contar con protocolos que informen sobre las características propias de cada población, desarrollados en conjunto con culturas de similar raigambre, a la vez que, en forma económica - tanto en recursos 
humanos como materiales - perfilar la toma de decisiones individuales, institucionales y de políticas sociales, educativas y sanitarias destinadas a estos grupos etarios.

En los estudios que sustentan este manual se indagó además el consumo de alcohol y marihuana en adolescentes, y se analizó la posible relación con los síndromes psicopatológicos y el bienestar subjetivo, obteniéndose así perfiles sobre factores de riesgo y de protección, ligándolos al consumo y la psicopatología, además de cuán bien se sienten. Estos perfiles agilizan la detección de posibles subgrupos de jóvenes más vulnerables, sobre los que se ha de actuar con mayor prontitud; sabemos cuán imperioso se vuelve esto en edades tan sensibles y cambiantes.

El protocolo ADA contiene el autoinforme, como instrumento de autovaloración, y una encuesta sociodemográfica, que integra el Índice de Nivel Socioeconómico (INSE), realizada por el Centro de Investigaciones Económicas del Uruguay. El protocolo ha tenido sus bases en la estrategia de evaluación y hallazgos -en población juvenil- desarrollados por Achenbach (1991), Achenbach y Edelbrock (1978, 1987), Achenbach et al (1987), Achenbach et al (2002), Quay (1977), Conners $(1970,1998)$ y Goodman (1997), lo que ha permitido contar con un número importante de antecedentes, a la vez que con las discusiones metodológicas imprescindibles en este tipo de aproximaciones.

A los estudios de similar sustento metodológico se ha sumado el análisis de resultados de trabajos con técnicas clásicas que indagan sobre los síndromes encontrados en las investigaciones, es así que, se tomaron como base los que estudiaban depresión, ansiedad, problemas de pensamiento, inmadurez, disocialidad, problemas de atención, miedo, consumo de sustancias, problemas de regulación emocional, problemas de comportamiento, entre otros, además de bienestar psicológico y resiliencia (Diener et al, 2003, 2006; Ryff, 2014; Cummins, 2003; Wagnild \& Young, 1993). Todo lo cual dio lugar, en una fase del desarrollo, a la inclusión de ítems que refieren a tópicos que han resultado significativos en los perfiles de las poblaciones estudiadas.

El objetivo del proyecto fue desarrollar un instrumento de evaluación para jóvenes - de entre 12 y 18 años, de ambos sexos-, que permita obtener un perfil psicológico general del adolescente en sus aspectos más prosociales, a la vez que informe sobre la existencia de problemas psicopatológicos, a partir de un cuestionario con ítems preestablecidos y con una escala tipo Likert, en el formato de autorespuestas.

El protocolo se completa con encuestas específicas y ad negocium, para cada asunto específico que se busque indagar, en estos estudios se han incluido las referidas a comportamientos adictivos -en especial alcohol y marihuana-, así como resiliencia y bienestar psicológico subjetivo.

\section{El protocolo ADA contiene:}

\section{- Encuesta sociodemográfica.}

\section{- Autoinforme de Adolescentes.}

- Encuestas específicas según las necesidades de la población en estudio, i.e. consumo de sustancias, resiliencia, bienestar, etc.

En los inicios se trabajó con versiones impresas en papel, para ir incorporando la versión digital, que es a la que se hace referencia en este manual. No obstante, podría -si se necesita- proporcionarse en formato papel, el protocolo fue diseñado para posibilitarlo. En la versión digitalizada se logra cargar las respuestas en un sistema que hace más ágil la obtención de perfiles por parte de los investigadores, una vez cumplidas las instancias de autorización paterna. También se cuenta con una versión abreviada que puede ser útil para los casos de estudios con población general, a la que se administra otros instrumentos y se busca además obtener un perfil básico desde el punto de vista psicopatológico y, si así lo requieren, el cuestionario sobre bienestar subjetivo.

La corrección del protocolo se realiza de forma manual o electrónica, con comunicación al Equipo de Investigación, quien hará las devoluciones del caso a aquellos usuarios identificados como tales que hayan cumplido con las instancias planteadas en los consentimientos informados - en sus dos formatos- para salvaguardar el manejo de los datos individuales.

\subsection{Bases conceptuales e instrumentales}

El presente proyecto se sustenta conceptualmente en el importante acervo de investigación y desarrollos metodológicos e instrumentales del sistema de evaluación basada empíricamente de Thomas M. Achenbach (1978) y colaboradores desde los años 70 al presente, con estudios que abarcan varios países y culturas. Los trabajos de los grupos españoles liderados por Lemos, Fidalgo, Calvo y Menéndez (1992), López Soler y colaboradores (1996, 2009) y Sánchez Meca y colaboradores (2011). A su vez, han tenido un importante aporte los estudios con el SDQ de Goodman (1997, 1999, 2001), Goodman, Meltzer y Bailey (1998) y Goodman, Lamping y Ploubidis (2010). Se inscriben dentro de los estudios que enmarcan este desarrollo instrumental, además de los señalados, las derivaciones de los trabajos de Verhulst en Alemania (Ferdinand \& Verhulst, 1995).

El sistema propuesto por Achenbach $(1995,2020)$, Achenbach, Dumenci y Rescorla (2002) se diferencia de los más clásicos Manual Diagnóstico y Estadístico de los Trastornos Mentales (DSM IV-TR y 5) de la Asociación Americana de Psiquiatría (APA, 2002 y 2013) y la Clasificación Internacional de Enfermedades (CIE 10 y CIE 11 -versiones preparatorias-) 
de la Organización Mundial de la Salud (OMS, 1992 y 2020) y otras gnosografías en que las bases de la investigación empírica son el sustento, en tanto establece ascender a través de los datos a la conceptualización del caso, en lo que da muy acertadamente en llamar "el camino de la tierra al cielo". Con este sistema se han realizado variados estudios alrededor del mundo, con edades que van desde la infancia a la adultez mayor, y una importante estructura de trabajo con informantes calificados. Un trabajo que abrió puertas a una manera de mirar la psicopatología e inspiró muchas investigaciones en diversos ámbitos, que, como este protocolo, buscaron incluir las propias idiosincrasias de las poblaciones iberoamericanas y contener en forma dinámica otras variables, tanto referidas a la psicopatología como a los factores protectores.

Además de las posibilidades de obtener perfiles específicos conjuntamente con los generales, desde los datos de los propios jóvenes y comparándolos con las poblaciones de las que forman parte, este sistema provee información sobre estructuras macro o superestructuras, como es el caso de los Síndromes Internalizantes y Externalizantes (Verhulst et al, 2003; Lemos, 2003; Rescorla et al, 2007; Thurber \& Sheehan, 2012; Achenbach, 2020).

Siguiendo la metodología señalada, se han desarrollado estudios en Montevideo y en capitales del interior y zonas suburbanas, tanto con población general como con poblaciones consideradas de riesgo (Daset et al, 1998; Daset et al, 2015; Fernández et al, 2017), a lo que se sumó una muestra clínica.

Plantear el desarrollo de un instrumento de evaluación psicológica supone atender a algunos asuntos centrales: los que refieren al modelo de sustento del instrumento -en este caso la evaluación basada empíricamente-; los relativos a los aspectos psicométricos -el modelo de abordaje metodológico y estadístico-; y, por último, los que refieren al propio instrumento -Autoinforme de Adolescentes-, su utilidad y alcance, en cuanto a las áreas centrales que indaga. En el protocolo ADA, en la parte de autoinforme, se proponen reactivos que buscan conocer aspectos referidos a pensamientos, emociones y comportamientos de los adolescentes, en el marco dado por variables sociodemográficas, académicas, familiares y de hábitos.

\subsection{Instrumento}

El instrumento que se desarrolló es el Autoinforme para Adolescentes. Para evaluar las variables implicadas en los objetivos, se utiliza un cuestionario, sobre el que se establecen las siguientes consideraciones:

El protocolo ADA se organiza en tres secciones básicas y otras que pueden ser adicionadas según el objetivo del estudio. En la primera sección se recoge información sobre datos sociodemográficos y de rendimiento académico, con la finalidad de establecer un perfil con datos básicos y contextuales; se incluyen ítems con información respecto a la conformación del grupo familiar, nivel de educación formal de los padres, actividades laborales y rendimiento académico del individuo.

Los ítems se completan con reactivos que indagan aspectos de orden prosocial, resilientes, relativos a fortalezas, afrontamiento, proyecto de vida y deseabilidad social; presenta ítems sobre comportamientos desadaptados o de tipo psicopatológico, que suponen muchos de ellos sufrimiento psíquico.

Lo que se solicita es la autovaloración que hace el joven, a partir de su autopercepción y, la mayoría de las veces, se le ofrece como punto de comparación a sus propios pares, en un formato de enunciado del tipo: "En relación con otras personas de tu edad, cómo...”. 


\section{Desarrollo del instrumento}

El protocolo ADA se fue construyendo a partir de proyectos de investigación y fases dentro de los mismos, sobre la base de que se quería analizar una forma viable y eficiente de evaluar a adolescentes en diferentes contextos, que cumpliera con los requisitos de economía de recursos, atendiendo a que las poblaciones del percentil más bajo socioeconómicamente no siempre podían contar con un diagnóstico de lo que les ocurría más que las consecuencias o la propia pobreza y exclusión. Muchas herramientas eran muy caras, poco accesibles para obtener los perfiles una vez completas, y en un lenguaje que les era ajeno o poco claro.

\subsection{Fases preliminares del ADA}

Primera fase: se llevaron a cabo revisiones bibliográficas sobre aspectos relativos a problemas mentales en adolescentes a partir del análisis de investigaciones en la materia, atendiendo a: los instrumentos de evaluación y sus características, y los resultados en poblaciones juveniles. Los criterios para la revisión bibliográfica sistemática (RS) fueron:

- De inclusión: estudios con adolescentes; con técnicas de evaluación psicológica y psicopatológica; con resultados en los que se constaran la validez y fiabilidad; entre los años 2000 y 2017. Muestras de población general y clínica. Idiomas: inglés, español y portugués.

- De exclusión: adultos o mayores de 21 años y niños menores de 9 años. Estudios con instrumentos de evaluación cualitativa. Estudios sin validación psicométrica alguna.

Las palabras clave y sus combinaciones fueron: 1 . adolescentes o jóvenes; 2. psicopatología, taxonomías, síndromes empíricos, factores riesgo, vulnerabilidad; 3 . resiliencia, bienestar psicológico, calidad de vida, factores de protección; y 4. consumo de alcohol y marihuana, uso de sustancias, drogas.

Las bases consultadas: APA, Scopus, Scielo, Ebsco, Medline, PubMed, Web of Science, Portal Timbó. 
Las conclusiones de esa RS permitieron, conjuntamente con los estudios que ya se llevaban a cabo en la línea de investigación, discriminar algunos de los temas centrales sobre los que se proyectaba indagar: ansiedad, depresión, autolisis, autolesión, quejas somáticas, TDAH, problemas de pensamiento, antisocialidad, problemas de ingesta, problemas del sueño, comportamiento adictivo, abuso -acoso- bullying, autorregulación/autocontrol, bienestar psicológico, prosocialidad y resiliencia.

Se construyó un banco de ítems conformado por 958 reactivos, agrupados por temas; se hizo el primer análisis a la luz de los sistemas de clasificación: Manual Diagnóstico y Estadístico de los Trastornos Mentales (DSM-IV-TR) de la Asociación Americana de Psiquiatría (APA) en su cuarta versión revisada (2002), la quinta versión DSM-5 (APA, 2013) y la Clasificación Internacional de Enfermedades (CIE-10) de la Organización Mundial de la Salud (OMS, 1992). Se eliminaron ítems según los siguientes criterios: juicio clínico, redundancia y no pertinencia del ítem; se obtuvieron 145 reactivos que fueron los iniciales de la primera protocolización.

Segunda fase: se realizó una revisión del protocolo por parte de 5 jueces expertos (con experiencia en evaluación psicológica y desarrollo, adaptación instrumental e investigación), alcanzando un acuerdo inter-jueces del $92 \%$. Luego de incorporar las devoluciones de los jueces se realizó una nueva reunión con expertos. Seguidamente, se procedió a trabajar bajo la dinámica de grupo focal, con 11 jóvenes de entre 12 y 17 años, con el objetivo de analizar: comprensibilidad, calidad de las consignas, pertinencia de tiempos y formatos, y qué entendían que buscaba indagar cada reactivo (se usaron para ello 2 protocolos, el primero el ADA y el otro construido a tales efectos).

Al final y tras un descanso, se propuso una instancia de discusión grupal donde se expu $\urcorner$ sieron las consideraciones que merecía el ADA y se generó un diálogo sobre asuntos que fueron relevantes o sobre los que a su entender no había ítems. La valoración fue positiva; debido a los planteos se reformularon algunos reactivos, especialmente por el uso de términos más propios de los destinatarios, se quitaron los iterativos y otros elementos que generaban incomodidad. Luego de incluir los resultados del primer grupo focal y obtener una nueva versión del instrumento se realizó un segundo grupo focal, con 30 adolescentes, siguiendo el mismo procedimiento.

\subsection{ADA versión 117 ítems}

Se realizó un análisis de todos los insumos obtenidos y se elaboró un protocolo con 117 ítems y una encuesta sociodemográfica y de aspectos de salud, vínculos, resolución de problemas en el hogar y uso de internet y videojuegos.
En el desarrollo instrumental se siguieron las directivas de la EFPA (Muñiz, Elosua \& Hambleton, 2013), atendiendo especialmente a:

- Corrección lingüística, cuidando los modismos de los jóvenes y términos ambiguos;

- Adecuación práctica, que implicó indagar sobre: formato del instrumento, tiempo y aspectos de la administración;

- Reconocimiento de las reacciones que provoca el protocolo ADA;

- Estimación de la capacidad explicativa de las consignas y adecuación de su extensión;

- Inclusión de nuevos ítems

- Obtención de un primer resultado de las respuestas que ofreciera el grupo a los ítems;

- Indagación sobre rechazos o reactivos que les resultaran incomprensibles o molestos.

Esta fase permitió, además, elaborar un instructivo de trabajo para los administradores del protocolo ADA; formar a quienes administran la técnica con tres sesiones extensas teórico-prácticas, previas al estudio piloto; se organizaron los protocolos, los materiales requeridos y los sistemas de registro.

Para la construcción del cuestionario de autoreporte ADA (Daset et al., 2015) y el estudio de sus propiedades psicométricas, se siguieron las normas para el desarrollo y revisión de estudios instrumentales (Carretero-Dios \& Pérez, 2007). Se desarrollaron las seis primeras -de las siete fases de la normativa- a saber: justificación del estudio, delimitación conceptual del constructo a evaluar, construcción y evaluación cualitativa de los ítems, análisis de los ítems, estudio de la dimensionalidad del instrumento o estructura interna, estimación de la fiabilidad y obtención de evidencias externas de validez (Muñiz, Elosua \& Hambleton, 2013; Carretero-Dios \& Pérez, 2005). Este proyecto recibió el aval del Comité de Ética de la universidad y se trabajó con los consentimientos informados de padres, institución y de los propios jóvenes.

Participaron estudiantes de enseñanza media básica y medio superior de seis colegios de Montevideo. Los estudios secundarios en el país están estructurados en un ciclo básico (3 años) y uno superior ( 3 años) - post-primario- para edades de 12 a 18 años. Se administró en grupos originales de curso en la institución educativa, por un graduado en psicología y estudiantes avanzados entrenados. Se aseguró el anonimato de los adolescentes. El tiempo promedio de administración fue de 65 minutos y las respuestas se recogieron -manuscritasen un protocolo impreso individual. Para el análisis de datos, se utilizó el programa SPSS. 


\subsubsection{Estructura factorial}

En primer lugar, se llevó a cabo un análisis factorial exploratorio sobre la matriz de correlaciones policóricas, con el fin de determinar la estructura factorial del cuestionario. Dado que el coeficiente multivariado de curtosis mostró la ausencia de normalidad, ya que la probabilidad asociada a asimetría multivariada es significativa (Mardia, 1970), se interpreta entonces que la distribución se aleja de la normalidad de manera significativa y, por tanto, es un inconveniente crítico para el análisis (Rodríguez \& Ruíz-Díaz, 2008). Lo anterior se confirma con el análisis de ítems, donde se reportó que el 33.4 \% presentan valores altos de asimetría y curtosis. Por este motivo se optó por realizar un AFE con la matriz policórica, con el método de extracción factorial de mínimos cuadrados no ponderados (ULS, por sus siglas en inglés Unweighted Least Squares), como elección de preferencia en este tipo de situaciones por su robustez, y se utilizó el método Promin para la rotación factorial (Maydeu-Olivares, Morera \& D’Zurilla, 1999), junto con el análisis factorial paralelo (PA) de Horn (1965), basado en el mínimum rank factor analysis (Timmerman \& Lorenzo-Seva, 2011).

La prueba de esfericidad de Barlett $(\chi 2=13935.8 ; \mathrm{p}<0.00)$ y el índice de Kaiser-MeyerOlkin (KMO) de adecuación muestral de .69 mostraron una pobre adecuación de los datos para la aplicación de un análisis factorial. El resultado del PA pone en evidencia la adecuación a una solución de siete factores.

Una vez establecida la solución factorial más adecuada se utilizó el método de rotación Promin (Lorenzo-Seva, 1999), con el objetivo de obtener una solución factorial simple. La matriz de saturaciones de la solución factorial obtenida permite identificar los contenidos de seis factores, explicando entre todos ellos el $33.34 \%$ de la varianza. Los resultados obtenidos evidencian un índice de bondad de ajuste malo ( $\mathrm{CFI}=0.43$; GFI $=0.92$ ). Con el fin de evaluar el ajuste de esta solución de siete factores se calculó la raíz media cuadrática residual (RMSR), obteniendo un valor de 0.052, indicando un buen ajuste, dado que el límite superior para considerar un ajuste aceptable, según el criterio de Kelly, es de 0.066. Dado el índice KMO descendido (0.69) y los valores de bondad de ajuste bajos, no se analiza el resultado de la factorización sugerida por el PA.

\subsection{ADA versión 98 ítems}

En la medida en que se avanzaba en el estudio de los análisis de los datos que se iban obteniendo, se veía la necesidad de depurar algunos ítems que no ofrecían información esclarecedora. Así se fueron construyendo las versiones hasta la definitiva. En cada una se analiza pros y contras y se trabaja tanto en los aspectos clínicos como estadísticos.
Se realiza un AFE para matriz policórica con el programa FACTOR (Lorenzo-Seva \& Ferrando, 2006) con la finalidad de estudiar el número de factores a extraer, en tanto posibilita el PA de Horn (1965). Se aplica un AFE, con la matriz de datos policórica de los 98 ítems seleccionados, de los 117 originales del ADA, con el método de estimación de factores de mínimos cuadrados no ponderados (ULS), con rotación oblicua, aplicando el método Promin de Lorenzo-Seva (1999). La prueba de esfericidad de Barlett fue signficativa $(\chi 2=$ 13935.8; $\mathrm{p}<0.00)$ y el índice KMO fue de .81, mostrando una muy buena adecuación de los datos para la aplicación de un análisis factorial.

\subsubsection{Estructura factorial}

En cuanto a la cantidad de factores a extraer, los resultados del PA de Horn (1965) ponen de manifiesto la posible extracción de seis dimensiones, por lo que la escala global podría ser considerada multidimensional. Se analiza la matriz de datos con un AFE (con Mplus 5) para indicadores categóricos u ordinales, usando el método de extracción de mínimos cuadrados ponderados (Schmitt, 2011), ajustados por la media y la varianza (WLSMW), con rotación geomin oblicua. En base al PA de Horn (1965) se recomienda la extracción de hasta siete factores, no obstante, siguiendo los principios de parsimonia y plausibilidad, se opta por la estructura más sencilla, clara y con valores de bondad de ajuste adecuados; se analizan entonces seis agrupaciones de ítems. Estas seis dimensiones se estudian desde el punto de vista clínico, y en relación con la validez del contenido, se observa que es la solución más adecuada. Seguidamente se eliminaron los ítems con pesos menores de .30 y los que tenían una diferencia menor de .15 en dos factores.

\subsubsection{Factores extraídos}

Se extrajeron seis factores:

\section{Tabla 1. Factores extraídos}

2. Disocial con comportamiento adictivo

3. Desregulación disruptiva del estado de ánimo y comportamiento disocial

4. Ansiedad socia

5. Resiliencia-prosocialidad 


\subsection{ADA versión 82 ítems}

Con el mismo criterio que se aplicó en versiones anteriores, se llegó a esta última versión atendiendo fundamentalmente a:

- Eliminar ítems que no aportaran a la construcción de los factores, con valores residuales en los distintos estudios.

- Obtener un listado de reactivos que fuera viable de ser respondido por los jóvenes en menor tiempo y que evitara confusiones con ítems de cierta similitud.

Se utiliza la versión de 82 ítems y se puntúa usando una escala de Likert de 5 puntos (04). Los síntomas psicopatológicos evalúan problemas emocionales, de comportamiento y relacionados con el pensamiento (por ejemplo, "Me siento triste y harto/a la mayor parte del tiempo"). El instrumento también incluye algunos ítems que se refieren al desarrollo positivo, incluyendo fortalezas, planificación de vida, habilidades de afrontamiento y deseabilidad social (por ejemplo, "Tengo confianza en mí mismo/a")

Una muestra no probabilística fue obtenida en un colegio ubicado en el área metropolitana de la ciudad de Montevideo, privado y religioso. Se utiliza esta muestra en particular dado su equilibrio en cuanto a edad y género. La muestra total consistió en 390 estudiantes. Dado que algunos estudiantes $(n=65)$ y/o sus padres decidieron no participar o no estaban en el centro educativo en el momento de la recopilación de datos, la muestra final resultó de 325 adolescentes y consistió en 172 chicas (53.2\%) y 153 varones (46.8 \%) de 12 a 18 años (M edad $=14.67 ; \mathrm{DE}=1.62$ ), con un buen nivel socioeconómico informado promedio.

\subsubsection{Estructura factorial para 82 ítems en área metropolitana}

En esta muestra, usando la versión de 82 ítems, las 6 dimensiones y su fiabilidad son las siguientes:

\section{Tabla 2. Estructura factorial para 82 ítems en área metropolitana}

\begin{tabular}{|l|c|}
\hline Factores & $\begin{array}{c}\text { Fiabilidad } \\
\text { (alfa de Cronbach) }\end{array}$ \\
\hline 1. Depresión-ansiedad & .94 \\
\hline 2. Disocial con comportamiento adictivo & .84 \\
3. Desregulación disruptiva del estado & .94 \\
de ánimo y comportamiento disocial & .92 \\
4. Ansiedad social & .93 \\
5. Resiliencia-prosocialidad & .87 \\
\hline 6. Obsesión-compulsión &
\end{tabular}

Tabla 3. Cargas factoriales para solución de seis factores con rotación oblimin

Ítems

F1

F2

F3

2. Aunque los demás piensen que soy delgado/a $0.510^{*}$

yo me veo gordo/a

$0.510^{*}$

3. Me siento demasiado culpable por cosas que

hago

4. Mis compañeros/as me amenazan o me

humillan por teléfono o internet

0.451 *

5. Me siento tan mal que quisiera hacerme daño $0.723^{\star}$

6. Pienso que voy a lograr lo que sueño

7. Mis compañeros/as me dejan de lado en todo $0.421^{*}$

8. He robado cosas o dinero de mi casa

9. Tengo la idea de que los demás me quieren

hacer daño

10. Siento vergüenza de mí mismo/a

11. Me obligo a vomitar después de comer

12. Tengo algunos movimientos que repito

(tocarme el pelo, mover el pie, etc.)

13. He robado cosas fuera de mi casa

14. Tengo ataques de rabia que no logro controlar

15. Me encanta ser el centro de atención

16. Debo ser perfecto/a en todo lo que hago

17. Golpeo a la gente a propósito

18. Hago sufrir a los animales si tengo ganas

19. Tengo la sensación de que otras personas me miran mal o hablan mal de mi

20. Cada vez necesito consumir más alcohol o drogas para sentir el mismo efecto

21. Pienso que soy torpe, incapaz o inferior a los demás

22. Siento que nadie me quiere

23. Estar con otras personas me hace sentir bien

24. Repito ciertas acciones (como tocar algo o

lavarme las manos) porque me tranquiliza

25. Cuando cometo un error estoy dispuesto/a

reconocerlo

26. Cuando tengo un problema, pienso que hay

una solución

27. Me lastimo el cuerpo a propósito (cortes,

heridas, etc.)

hago

29. He tenido ataques de pánico

30. Odio mi aspecto
$0.456^{*}$

$0.343^{*}$

0.764

0.750 *

$0.275^{\star}$

$0.662^{\star}$

0.553

$0.464^{\star}$

$0.331^{\star}$

$0.605^{\star}$

$.0 .990^{*}$

0.358

$0.683^{\star}$

0.791 *

$0.801^{\star}$

$0.274^{\star}$

$0.445^{*}$

$0.475^{\star}$

0.519

$0.826^{*}$

$0.484^{\star}$
$0.408^{*}$

$0.754^{\star}$ 


\section{tems}

F1

31. Hay ideas o imágenes que no puedo saca

de mi cabeza y no me gustan

32. Me siento muy solo/a

33. Me da miedo ir al liceo

$0.477^{\star}$

$0.761^{*}$

34. Discuto más violentamente que la mayoría

de las personas de mi edad

35. Pienso que me van a pasar cosas buenas

36. Siento ganas de causar algún tipo de daño a

las personas

37. He prendido fuego cosas que no debía

38. Por momentos siento que me va a dar un

ataque o me va a pasar algo malo

39. Siento que la gente me quiere

40. Se me hace difícil prestar atención por

mucho tiempo y eso me trae problemas

41. Me gusta ayudar a los demás

42. Me siento triste e infeliz la mayor parte de

tiempo

43. Amenazo a los demás

44. Tengo la idea de que algo en mi mente no

anda bien

45. Me cuesta estar quieto/a en mi asiento por mucho tiempo

46. Tengo miedo de pensar o hacer algo malo

47. Tengo ganas de vomitar (sin que el médico

encuentre la causa)

48. Me gustaría ser del otro sexo

49. Tengo confianza en mí mismo/a

50. Pienso en cómo quitarme la vida

51. Por temor a que se burlen de mí, no me

acerco a la gente

$0.746^{*}$

$0.686^{*}$

$0.566^{\star}$

$0.530^{\star}$

$0.528^{\star}$

$-0.623$

52. Soy más miedoso/a que las personas de m edad

53. Pienso que soy un fracaso

4. Recibo más insultos o bromas humillantes de las que puedo soportar

55. Tengo amigos/as que tienen problemas por
el consumo de drogas

56. Tengo dolores de cabeza (sin causa

aparente)

57. Destruyo las cosas de los demás

58. Si alguien se pelea conmigo, no le hago caso

59. La mayoría de mis problemas son por culpa de los demás

60. Cuando me enojo pierdo el control de lo

que digo o hago

61. Cuando tengo un problema, hago todo lo

que puedo para resolverlo

$0.639^{*}$
0.504

0.413

$.878^{\star}$

0.251

0.532 tems

62. Cuando estoy entre mucha gente tengo miedo de que se burlen de $\mathrm{m}$

3. Cuando tengo un problema, me sirve

escuchar otros puntos de vista

64. Me comporto como si fuera del sexo

opuesto

65. Aunque pasen cosas difíciles, puedo

encontrar un motivo para sonreír

66. Cuando estoy mal, me cuesta entender lo

que me pasa

67. Si tengo ganas de romper algo, me cuesta

controlarme

68. Para mí es difícil demostrar lo que siento

69. Siento miedo en espacios abiertos o en la

70. Cuando estoy mal, me ayuda estar con otras

personas (amigos, familia)

$\begin{array}{lllll}F 1 & F 2 & F 3 & F 4 & F 5\end{array}$

$0.452^{\star}$

0.583

71. Tengo que revisar las cosas que hago, para

(corrar con llave, etc.)

72. Evito ciertas cosas, lugares o actividades

que me dan miedo

73. Cuanto más me mandan a hacer algo, más

voy a tardar en hacerlo

$0.478^{*}$

p. Me siento mejor cuando hablo con otras

personas de mis problemas

75. Si alguien me pega primero, empiezo a

pegarle y no puedo para

76. He deseado estar muerto/a

77. Cuando empiezo a insultar, no puedo parar

78. Tengo miedo a tener miedo

79. Me peleo a golpes más seguido que los

demás

80. Pienso que necesito ayuda psicológica

81. Tengo miedo de que en mi familia se

contagien o enfermen

82. Antes de salir de casa tengo que revisar

varias veces mis cosas
$0.210^{*}$

$0.284^{\star}$

0.685

$0.650^{*}$

0.700

0.724

$0.591 *$ 
Tabla 4. Índices de bondad de ajuste para un modelo de seis factores

\begin{tabular}{ccccccc} 
Modelo & gl & $X^{2}$ & $X^{2} / g l$ & CFI & TLI & RMSEA \\
\hline 6 factores & 2844 & 3488.89 & 1.22 & 0.94 & 0.93 & 0.026
\end{tabular}

\subsubsection{Versión 82 ítems en muestra en contexto vulnerable}

Esta versión se aplicó en una organización sin fines de lucro, ubicada en un barrio de la periferia de Montevideo, que trabaja a través de talleres con adolescentes con consumo de alcohol y marihuana, ofreciendo apoyo psicológico y pedagógico. La muestra se compuso de 30 adolescentes (varones $50 \%$ y chicas $50 \%$ ), con una media de edad de 15 años (DE 1.68). La frecuencia de edades fue la siguiente: $46.7 \%$ adolescentes de 13 y 14 años, $23.3 \%$ de 15 y 16 años, y $30 \%$ entre 17 y 18 años. La muestra tuvo adolescentes de nivel socioeconómico bajo 30 \% y medio $70 \%$. En cuanto a la fiabilidad de esta versión, el alfa de Cronbach en las seis dimensiones va de .60 a .90, valores recomendados por Carretero-Dios y Pérez, 2005.

\subsubsection{Estructura factorial}

Con esta muestra se realizó una comparación con la muestra anterior $(\mathrm{N}=325)$ de población general. En primer lugar se utilizó la prueba de Shapiro-Wilk para examinar si las diferentes variables tenían una distribución normal. Los factores de ADA del 1 al 5 en esta muestra no estaban distribuidos normalmente porque son significativos en una escala de 0.01 ( $\mathrm{p}<0.01$ ). El factor 6 sí fue una variable distribuida normalmente $(\mathrm{p}=0.494)$. Para las variables que no estaban distribuidas normalmente, se realizó una prueba U de MannWhitney. Para el factor 6 se gestionó una prueba paramétrica (T).

Si se comparan las medias de las muestras del grupo de adolescentes vulnerables con la de población general se puede examinar la significancia de los siguientes factores ADA: factor 1 $(\mathrm{Z}=-3.50 ; \mathrm{p}=0.00)$, factor $2(\mathrm{Z}=-2.71 ; \mathrm{p}=0.01)$, factor $3(\mathrm{Z}=-2.51 ; \mathrm{p}=0.01)$ y factor $4(\mathrm{Z}$ $=-3.21 ; p=0.00$ ). Como se ilustra en la tabla 5 , se puede notar que existe una diferencia significativa entre las medias de ambas muestras en cuanto a depresión-ansiedad, disocial con comportamiento adictivo, desregulación disruptiva del estado de ánimo y comportamiento disocial, y ansiedad social. No hay diferencia significativa para el factor de resiliencia-prosocialidad $(-1.03 ; \mathrm{p}=0.30)$. Los resultados mostraron que no hay diferencia significativa entre las medias del factor 6 para las dos muestras $(t=1.60 ; \mathrm{p}=0.11)$

\section{Tabla 5. Diferencias de medias muestra contexto vulnerable y población general}

\begin{tabular}{|lcl|} 
Factores & $Z$ & $P$ \\
\hline F1: Depresión-ansiedad & -3.50 & .00 \\
\hline F2: Disocial con comportamiento adictivo & -2.71 & .01 \\
\hline $\begin{array}{l}\text { F3: Desregulación disruptiva del estado de ánimo y } \\
\text { comportamiento disocial }\end{array}$ & -2.51 & .01 \\
\hline F4: Ansiedad social & -3.21 & .00 \\
\hline F5: Resiliencia-prosocialidad & -1.03 & .30
\end{tabular}

Además de los estudios de distribución normal de la muestra, se realizó una comparación entre las medias de cada factor de ADA de la muestra original (Daset et. al., 2015) y la muestra con población vulnerable con una prueba $\mathrm{T}$ independiente. Se aprecia una diferencia significativa entre las medias para los siguientes factores: $\mathrm{F} 1(\mathrm{~T}=3.19 ; \mathrm{p}=0.003), \mathrm{F} 2(\mathrm{~T}=2.96$; $\mathrm{p}=0.006), \mathrm{F} 3(\mathrm{~T}=3.66 ; \mathrm{p}=0.001), \mathrm{F} 4(\mathrm{~T}=3.24 ; \mathrm{p}=0.003)$ y F6 $(\mathrm{T}=6.32 ; \mathrm{p}<0.001)$. Como se ilustra en la tabla 6 , se nota una diferencia significativa entre las medias de la muestra de población vulnerable y la muestra original de ADA con respecto a la depresión-ansiedad, disocial con comportamiento adictivo, desregulación disruptiva del estado de ánimo y comportamiento disocial, ansiedad social y obsesión-compulsión. No hay diferencia significativa para el factor de resiliencia-prosocialidad $(\mathrm{T}=0.86 ; \mathrm{p}=0.40)$.

\section{Tabla 6. Diferencias de medias entre muestras de población vulnerable y muestra original ADA}

\begin{tabular}{|l|r|r|}
\hline Factores & $\mathrm{T}$ & $\mathrm{P}$ \\
\hline F1: Depresion-ansiedad & 3.19 & .003 \\
\hline F2: Disocial con comportamiento adictivo & 2.96 & .006 \\
\hline F3: Desregulación disruptiva del estado de ánimo & 3.66 & .001 \\
\hline F4: Ansiedad social & 3.24 & .003 \\
\hline F5: Resiliencia-prosocialidad & 0.86 & .396 \\
F6: Obsesión-compulsión & 6.32 & .000
\end{tabular}




\subsection{ADA versión abreviada de 24 ítems}

Se trata de una versión abreviada del ADA, que se elabora con el fin de poder realizar una toma de forma más sencilla y brindarle un mayor alcance. Se sustenta en los siguientes criterios:

- Acceder a un cribado básico con gran economía del recurso tiempo en los jóvenes.

- Permitir realizar una aproximación antes de administrar pruebas específicas.

Para obtener esta escala abreviada se tomaron los cuatro ítems con mayor carga factorial y se corrió un Análisis Factorial Confirmatorio (AFC) con 24 ítems, obteniéndose índices de ajustes muy buenos, como se observa en la tabla 7 . Confirmando la existencia de seis factores con cargas factoriales por encima de 0.40 en todos los casos y fiabilidades cercanas a $0.70 \mathrm{o}$ mayores.

Esta versión fue testeada en la periferia de Montevideo, en una de las zonas más pobres del departamento, caracterizada por la presencia de varios asentamientos irregulares, con problemáticas de desempleo, informalidad laboral, dificultad de acceso a los servicios, hacinamiento, entre otros. En la investigación participaron 107 adolescentes (59 sexo masculino y 48 sexo femenino), con edades comprendidas entre 12 y 15 años $(M=13.55$; $\mathrm{DE}=0.94$ ), procedentes de ciclo básico de dos liceos, seleccionados por muestreo intencional. El $43 \%$ eran estudiantes de primer año, el $28 \%$ de segundo y el $29 \%$ de tercero.

Se trata de dos instituciones educativas que ofrecen educación media básica. Los estudiantes pasan en promedio 6 horas curriculares de clase, además de las horas adicionales de clases de apoyo y/o actividades extracurriculares, las cuales poseen un elevado peso en ambos casos. Asimismo, realizan un trabajo con las familias y la comunidad, buscando la participación y el acompañamiento en la educación de sus hijos, son consideradas instituciones modélicas.

Se corrió un AFE con los 118 ítems originales con el programa Mplus para datos categóricos, con una muestra de 356 sujetos, encontrándose seis factores (Daset, Fernández, Costa-Ball, López-Soler \& Vanderplasschen, 2015; Hughes, 2019).

Tabla 7. Índices de bondad de ajuste para un modelo de seis factores con cuatro ítems cada uno

\begin{tabular}{ccccccc} 
Modelo & $\mathrm{gl}$ & $\mathrm{X}^{2}$ & $\mathrm{X}^{2} / \mathrm{gl}$ & $\mathrm{CFI}$ & $\mathrm{TLI}$ & RMSEA \\
\hline 6 factores & 237 & 320.12 & 1.35 & 0.95 & 0.96 & 0.031
\end{tabular}

Tabla 8. Cargas factoriales para la solución de seis factores con rotación oblimin y fiabilidad

\section{ADA}

Hago sufrir animales si tengo ganas

Cada vez necesito consumir más alcohol o drogas para sentir el mismo efecto

He prendido fuego cosas que no debía

He robado cosas o dinero fuera de mi casa

Pienso en cómo quitarme la vida

He deseado estar muerto/a

Me siento tan mal que quisiera hacerme daño

Me siento triste e infeliz la mayor parte del tiempo

Por temor a que se burlen de mí, no me acerco

mucho a la gente

Cuando estoy entre mucha gente tengo miedo de

que se burlen de mí

Recibo más insultos o bromas humillantes de las

que puedo soportar

Me da miedo ir al liceo

Cuando tengo un problema, pienso que hay una solución

Cuando tengo un problema, hago todo lo que

puedo para resolverlo

Aunque pasen cosas difíciles, puedo encontrar un motivo para sonreír

Pienso que me van a pasar cosas buenas

Cuando empiezo a insultar, no puedo parar

$\begin{array}{llll}\text { F2 } & \text { F3 } & \text { F4 } & \text { F5 }\end{array}$

Si alguien me pega primero, empiezo a pegarle y

no puedo parar

Si tengo ganas de romper algo, me cuest

controlarme

Amenazo a las demás personas

Antes de salir de casa tengo que revisar varias

veces mis cosas

$\mathrm{F} 1$

0.79

0.77

0.68

0.50

\subsection{9}

0.87

0.85

0.75

Tengo que revisar las cosas que hago, para

comprobar que están bien (cerrar con llave, etc.)

Evito ciertas cosas, lugares o actividades que me

dan miedo

0.75

Repito ciertas acciones (como tocar algo o lavarme las manos) porque me tranquiliza 


\section{3. Ámbitos de aplicación}

El ADA puede ser utilizado en una variedad de contextos con la finalidad de detección temprana de dificultades a nivel psicológico y también de identificación de fortalezas en los adolescentes. Tiene una clara finalidad de uso en la prevención y puede ofrecer un insumo eficiente y de calidad en la elaboración de políticas en diferentes ámbitos. Además, posibilita obtener perfiles diferenciales en poblaciones como instituciones educativas, deportivas o con grupos específicos

\subsection{Educativo}

El ADA fue especialmente desarrollado para atender a las necesidades del ámbito educativo. En dicho ámbito la técnica permite la administración colectiva y la obtención de información de utilidad para profesores y padres. Los adolescentes pasan la mayor parte de su tiempo en el espacio educativo, por lo tanto es favorable contar con un instrumento de evaluación que permita un abordaje preventivo primario. En dicho lugar se pueden realizar evaluaciones periódicas sistemáticas, que permitan no solo atender casos particulares, donde se detecte vulnerabilidad, sino intervenciones grupales y diseño de talleres para esa etapa etaria.

\subsection{Clínico y de la salud}

En el ámbito clínico, el ADA es una técnica de evaluación que puede usarse al inicio del proceso terapéutico y permite contar con una información global de la persona evaluada. A su vez, el ADA es útil como complemento de otros métodos de obtención de información clínica, por ejemplo, las entrevistas clínicas diagnósticas, y permite elaborar una estrategia diagnóstica al actuar como técnica de screening, donde el profesional rápidamente puede seleccionar tests específicos según los resultados obtenidos. En el sistema de salud provee información valiosa sobre aspectos de la salud mental y las fortalezas de la adolescencia, de manera clara y rápida. 


\subsection{Forense}

El ADA permite una evaluación global tanto de las vulnerabilidades como de los recursos psicológicos de las personas, en ese sentido es útil en el ámbito forense para los profesionales que realizan las evaluaciones de los adolescentes y deben, con cierta prontitud, tomar decisiones que abarquen variados aspectos de la vida futura del joven o asesorar al ámbito jurídico sobre variables que requieren muy diversa atención.

\subsection{Académico, de investigación}

El ADA se está utilizando en el campo de la investigación académica con muy buenos resultados. Se destaca la amplitud de sus constructos y la característica dimensional de evaluación, con criterios diagnósticos equivalentes al DSM-5 y al DSM-IV TR, con posibilidad de realizar estudios comparativos con los nuevos modelos psicopatológicos. 


\section{Consideraciones éticas}

El uso y aplicación de técnicas psicológicas con humanos se rige por principios establecidos para proteger a las personas participantes. Se presentan aquí lineamientos generales con el fin de guiar la aplicación de la técnica a los profesionales que tienen la tarea de trabajar directamente con adolescentes.

Es importante, antes de toda aplicación de una técnica, verificar que la misma esté validada y sea fiable para la población objetivo.

Se debe estar debidamente capacitado para poder administrar e interpretar la técnica. Además, es importante que su uso esté determinado por objetivos claros y fundamentados.

Se debe asegurar la confidencialidad de los resultados de la técnica, así como también la identidad y datos personales de las personas a las que se administra el instrumento.

Es importante brindar información clara a los participantes acerca de la finalidad de la evaluación y qué se hará con los resultados. Además, se deben explicar el procedimiento y las implicaciones para los sujetos participantes.

En el caso de la administración electrónica, se debe explicitar cómo se van a gestionar los protocolos y el acceso y resguardo informático.

La información obtenida de otras fuentes y mediante otros métodos puede ayudar a verificar y complementar los resultados obtenido en el ADA. Las otras fuentes de información pueden ser instrumentos adicionales específicos, entrevistas diagnósticas realizadas por un profesional competente con el adolescente, padres y profesores, la historia clínica de la persona, entre otros. 


\subsection{Consentimiento}

Antes de la aplicación de los protocolos (encuesta sociodemográfica + ADA) se debe solicitar el consentimiento informado activo de la institución donde se llevará a cabo la toma de datos, así como también de los adultos referentes a cargo de los menores, y el consentimiento de los propios adolescentes.

Se podrá solicitar a los investigadores, vía correo electrónico, un formato de consentimiento informado, el mismo debe ser adaptado a la institución que corresponda y al ámbito de aplicación específico.

Si la toma de datos es parte de una investigación académica, la misma debe realizar el trámite correspondiente, previo a la aplicación de los protocolos, ante el Comité de Ética de la universidad o institución que corresponda. 


\section{Administración del protocolo ADA}

Las pautas de aplicación fueron pensadas con el objetivo de contar con una administración lo más estandarizada posible para que los resultados sean precisos.

Se sugiere que antes de la aplicación de la técnica el examinador esté familiarizado con la misma y con la consigna. Así mismo debe leer cuidadosamente el manual de aplicación con anterioridad.

Para responder a la prueba adecuadamente se deben descartar previamente dificultades de comprensión lectora, discapacidades intelectuales o físicas que impidan la correcta comprensión de la prueba o dar las ayudas correspondientes - por ejemplo, visuales o auditivas- y definir si el adolescente necesita de algún otro tipo de apoyo en la administración por ejemplo, donde la comprensión lectora es lenta o se ve dificultada por el ritmo de lectura.

El tiempo de administración puede variar según si se trata de adolescentes menores o mayores. Se sugiere controlar el tiempo de administración.

Previo a comenzar la administración, se sugiere explicar la tarea, leer la consigna y asegurarse de que todas las personas comprendieron. Es relevante explicar que no es una situación de examen y que no hay respuestas buenas o malas, sino que tendrán que responder sinceramente lo que cada persona entienda que debe ser. Es importante aclarar que el cuestionario incluye comportamientos muy variados, que no siempre se han tenido, es para todas las personas.

Establecer un buen rapport con los participantes es fundamental para obtener resultados válidos. Es esperable que durante la administración surjan preguntas o dudas sobre el llenado de los protocolos o sobre algún término que no se conozca. En ese tipo de casos, se deberá suministrar la información que describa mejor los ítems en el lenguaje apropiado, con cuidado de no sugerir o influir en las respuestas. 
Para la correcta administración de la técnica se deberá contar con un ambiente adecuado, sin ruidos distractores y con el material necesario. En el caso de la aplicación en formato papel, es importante la revisión final del protocolo, las respuestas incompletas, con omisiones o respuestas dobles invalidan el cuestionario. Un número elevado de estos casos afectará la fiabilidad y validez de la toma.

En el caso del uso de la técnica en versión papel, el administrador deberá contar con dos sobres, uno para la lista de participantes con el código de identificación, la misma será confidencial, y otro para el protocolo mismo, el cual no contendrá ningún tipo de información personal. Se usará un código en el cuestionario (arriba de la primera hoja) por participante.

Algunas preguntas podrían llegar a generar algún tipo de incomodidad o ansiedad en el participante, en ese caso se sugiere que se pueda hablar en privado con el adolescente, en el caso de instituciones educativas se podrá avisar al personal de apoyo. Se recuerda especialmente el derecho a interrumpir en cualquier momento la prueba sin tener ningún tipo de consecuencia.

\subsection{Normas de aplicación y corrección}

Se puede aplicar tanto de forma individual como colectiva. El protocolo cuenta con un instructivo con consignas sencillas que el participante deberá leer con atención:

"Lee con atención las premisas. Contesta con sinceridad, no dejes ninguna pregunta en blanco. Te presentamos una lista de frases. Lee cada frase y responde en qué medida estás de acuerdo. Marca con una cruz un solo casillero, según las siguientes opciones:"

\begin{tabular}{|c|c|}
\hline NADA de acuerdo & marca una cruz en el 0 \\
\hline MUY POCO de acuerdo & marca una cruz en el 1 \\
\hline POCO de acuerdo & marca una cruz en el 2 \\
\hline BASTANTE de acuerdo & marca una cruz en el 3 \\
\hline MUY de acuerdo & marca una cruz en el 4 \\
\hline
\end{tabular}

\subsubsection{Versión en papel}

Materiales: protocolo ADA, papel, lápiz, goma.

Procedimiento: Se entrega al individuo el protocolo en papel, junto con los demás materiales señalados. Luego se prosigue a leer las instrucciones y contestar dudas que puedan surgir. Se aclara a los participantes que la tarea no debería llevar más de 45 minutos, aunque pueden solicitar 15 minutos adicionales. Es necesario que acompañe la tarea un individuo previamente preparado para responder posibles dudas.

\subsubsection{Versión electrónica}

Materiales: dispositivo electrónico con conexión a internet (celular, tablet, computadora), conexión a internet, tener preparado el link del cuestionario electrónico.

Procedimiento: Asegurarse de que todos los participantes cuenten con el dispositivo electrónico, junto con el link y una conexión a internet adecuada. Una vez logrado esto, se solicita que abran el link y se leen las instrucciones. Es prudente que se cuente con la presencia de un profesional o asistente preparado previamente para responder posibles dudas. 


\section{Normas de interpretación}

Con el instrumento ADA se puede obtener la ubicación del sujeto de acuerdo a sus pares (cómo este se compara con las respuestas de otras personas de su edad) en seis diferentes factores de interés:

Tabla 9

\begin{tabular}{cl} 
Factor & Definición del factor \\
\hline 1 & Depresión-ansiedad \\
2 & Disocial con comportamiento adictivo \\
3 & Desregulación disruptiva del estado de ánimo y comportamiento disocial \\
4 & Ansiedad social \\
5 & Resiliencia-prosocialidad \\
6 & Obsesión-compulsión
\end{tabular}

Las puntuaciones más altas en estos factores indican mayor severidad con la excepción del factor de resiliencia, donde mayores puntuaciones indican mayores factores de protección y prosocialidad.

Para calcular cada factor se deben sumar los valores correspondientes a cada respuesta de los ítems específicos del factor. En términos generales, los valores a sumar son los siguientes de acuerdo con la respuesta:

\begin{tabular}{|c|c|}
\hline NADA de acuerdo & 0 \\
\hline MUY POCO de acuerdo & 1 \\
\hline POCO de acuerdo & 2 \\
\hline BASTANTE de acuerdo & 3 \\
\hline MUY de acuerdo & 4 \\
\hline
\end{tabular}


Existe un ítem (70) donde el valor a sumar se invierte de la siguiente forma:

\begin{tabular}{|c|c|}
\hline NADA de acuerdo & 4 \\
\hline MUY POCO de acuerdo & 3 \\
\hline POCO de acuerdo & 2 \\
\hline BASTANTE de acuerdo & 1 \\
\hline MUY de acuerdo & 0 \\
\hline
\end{tabular}

Tabla 10

Factor

1 - Depresión-ansiedad Ítems

2- Disocial con comportamiento adictivo $1,2,3,4,5,10,11,22,27,29,30,31,32,38,42$ $46,47,50,53,56,66,76,80$

- Disocial con comportamiento adictivo $13,15,16,18,20,57,67$

3 - Desregulación disruptiva del estado $\quad 14,17,34,36,37,43,44,45,48,55,60,64,67$, de ánimo y comportamiento disocial $\quad 73,75,77,79$

4 - Ansiedad social

$7,9,19,21,33,51,52,53,54,59,62,68,69,78$

5 - Resiliencia-prosocialidad

$6,23,25,26,28,35,39,41,49,61,63,65,70,74$

6 - Obsesión-compulsión

24, 40, 70 (puntuación inversa) 71, 72, 74, 81, 82

\section{Ejemplo de puntuación y análisis:}

Un chico de 15 años obtiene las siguientes respuestas a los ítems del factor 2 (disocial con comportamiento adictivo):

Tabla 11

\begin{tabular}{|c|c|c|}
\hline Ítem 13 & Nada de acuerdo & 0 \\
\hline Ítem 15 & Muy poco de acuerdo & 1 \\
\hline Ítem 16 & Nada de acuerdo & 0 \\
\hline Ítem 18 & Bastante de acuerdo & 3 \\
\hline Ítem 20 & Nada de acuerdo & 0 \\
\hline Ítem 57 & Nada de acuerdo & 0 \\
\hline Ítem 67 & Muy poco de acuerdo & 1 \\
\hline
\end{tabular}

La suma de las puntuaciones arroja un total de 5 . Con este valor se puede ir a las tablas de baremos y a los anexos para comparar con las respuestas de jóvenes de su edad en este factor

El valor promedio para su grupo de edad en el factor 2 es de 2.64, con un desvío estándar de 2.46. Esto indica que su puntuación de 5 está un desvío estándar por sobre la media. A su vez, los percentiles indican que el 87 \% de los varones de su edad puntúan por debajo de 5 . Esto indica que esta puntuación es bastante elevada para dicho factor. 


\section{Justificación estadística}

Con el fin de evaluar el comportamiento normal de las variables, en primer lugar, se realizó un análisis descriptivo de los ítems. Se evaluó la asimetría y curtosis, y se complementó con la prueba Kolmogorov-Smirnov. En segundo lugar, a través del estadístico alfa de Cronbach se estimó la consistencia interna de los indicadores. Con el fin de comprobar la es $\neg$ tructura factorial inicial, se realizó un AFE y un análisis de confiabilidad interna de la misma.

El alfa de Cronbach para los dominios ADA oscila entre 0.70 y 0.90 (Daset et al 2015). Se obtienen seis factores del ADA 82, que se describen como: factor 1, depresión-ansiedad; factor 2, disocial con comportamiento adictivo; factor 3, desregulación disruptiva del estado de ánimo y comportamiento disocial; factor 4 , ansiedad social; factor 5 , resiliencia-prosocialidad; y factor 6, obsesión-compulsión. El alfa de Cronbach fue de 0.94 para F1; 0.84 para F2; 0.94 para F3; 0.92 para F4; 0.93 para F5; y 0.88 para F6.

\subsection{Validez concurrente}

Para la validación concurrente se aplicaron los siguientes instrumentos: el cuestionario de Ansiedad Estado/Rasgo (State-Trait Anxiety Inventory, Self evaluation questionnaire, STAI; de Spielberger, Gorsuch \& Lushene, 1970), en su versión española Guillén-Riquelme y Buela-Casal (2011). El Y-BOCS Escala de Obsesiones y Compulsiones de Yale-Brown (Yale-Brown Obsessive Compulsive Scale) de Woody, Steketee y Chambless (1995), en su adaptación española de Ulloa, De la Peña, Higuera, Palacios, Nicolini y Ávila (2004). El cuestionario de Capacidades y Dificultades (Strengths and Difficulties Questionnaire, SDQ) de Goodman (1997) adaptado al español por Blumert (2003). El Índice de Bienestar Personal (Personal Well-being Index) de Cummins, Eckersley, Pallant, Van Vugt y Misajon (2003) en su adaptación para Chile de Alfaro, Valdenegro y Oyazún (2013).

El análisis de fiabilidad se realizó mediante el estadístico alfa de Cronbach. Se realizaron las correlaciones entre las variables que componen cada factor del ADA con un instrumento correspondiente que indaga el mismo constructo, se presentan los resultados en la tabla 12. 


\subsection{Correlaciones entre síndromes del ADA y otras técnicas}

Correlaciones entre los síndromes del ADA y las escalas STAI, SDQ, PWI y Y-BOCS.

Tabla 12. Correlaciones entre síndromes ADA y otras técnicas

\begin{tabular}{llllll}
\hline Síndromes & STAI & SDQ & PWI & Y-BOCS \\
\hline F1: Depresión-ansiedad & $.733^{\star \star}$ & $.528^{\star \star}$ & & \\
$\begin{array}{l}\text { F2: Disocial con comportamiento adictivo } \\
\text { F3: Desregulación disruptiva del estado }\end{array}$ & & $.233^{\star \star}$ & \\
de ánimo y comportamiento disocial & & $.302^{\star \star}$ & \\
F4: Ansiedad social & $.636^{\star \star}$ & & & \\
F5: Resiliencia-prosocialidad & & $.338^{\star \star}$ & $.472^{\star \star}$ & \\
\hline F6: Obsesión-compulsión & & & & $.280^{\star \star}$
\end{tabular}

**Correlación significativa al nivel 0.01 (bilateral). 


\section{Baremos}

Para un análisis más claro de los casos se realizaron los baremos dividiendo la muestra total de ambos estudios empíricos ( $\mathrm{N}=688$ ) por sexo y dos grupos de edades, el primer grupo de adolescencia temprana, de 12 a 14 años, y el segundo de adolescencia tardía, de 15 a 18 años. Para los análisis de baremos se calcularon en primer lugar las medias de cada factor con su respectivo desvío estándar. Se presentan las tablas por percentiles según grupo de edad y sexo. Para cada factor se calcularon la media más un desvío típico y más dos desvíos, para cada grupo por sexo y edad, con la finalidad de que el lector menos avezado pueda visualizar más rápidamente si se está ante un posible caso. En el anexo 1 se presentan las tablas de baremos.

Los baremos se construyeron con las muestras de adolescentes escolarizados de entre 12 a 18 años, de ambos sexos, de la ciudad de Montevideo. Este es el contexto adecuado de visualización y aplicación de los baremos de la prueba. 


\section{Tablas según sexo y grupos de edad}

Tabla 13. Chicas de 12 a 14 años

\begin{tabular}{lccc|}
\hline Factores ADA & N & M & DE \\
\hline F1: Depresión-ansiedad & 225 & 13.53 & 12.29 \\
\hline F2: Disocial con comportamiento adictivo & 239 & 2.01 & 2.13 \\
\hline $\begin{array}{l}\text { F3: Desregulación disruptiva del estado de ánimo y } \\
\quad \text { comportamiento disocial }\end{array}$ & 233 & 9.76 & 8.41 \\
\hline F4: Ansiedad social & 233 & 9.84 & 8.03 \\
\hline F5: Resiliencia-prosocialidad & 230 & 38.60 & 8.93 \\
\hline F6: Obsesión-compulsión & 239 & 7.43 & 3.73
\end{tabular}

Tabla 14. Chicas de 15 a 18 años

\begin{tabular}{lccc|}
\hline Factores ADA & N & M & DE \\
\hline F1: Depresión-ansiedad & 137 & 16.16 & 13.59 \\
\hline F2: Disocial con comportamiento adictivo & 141 & 2.54 & 2.15 \\
\hline $\begin{array}{l}\text { F3: Desregulación disruptiva del estado de ánimo y } \\
\text { comportamiento disocial }\end{array}$ & 140 & 11.12 & 9.00 \\
\hline F4: Ansiedad social & 139 & 10.69 & 7.99 \\
\hline F5: Resiliencia-prosocialidad & 141 & 38.22 & 8.25 \\
\hline F6: Obsesión-compulsión & 141 & 6.90 & 3.48
\end{tabular}




\section{Tabla 15. Varones de 12 a 14 años}

\begin{tabular}{lccc|}
\hline Factores ADA & $\mathrm{N}$ & $\mathrm{M}$ & $\mathrm{DE}$ \\
\hline F1: Depresión-ansiedad & 181 & 12.28 & 13.46 \\
\hline F2: Disocial con comportamiento adictivo & 188 & 2.14 & 2.29 \\
\hline $\begin{array}{l}\text { F3: Desregulación disruptiva del estado de ánimo y } \\
\text { comportamiento disocial }\end{array}$ & 187 & 9.41 & 8.10 \\
\hline F4: Ansiedad social & 183 & 8.24 & 7.79 \\
\hline F5: Resiliencia-prosocialidad & 180 & 38.00 & 8.39 \\
\hline F6: Obsesión-compulsión & 189 & 7.25 & 3.65
\end{tabular}

\section{Tabla 18. Chicas de 15 a 18 años}

\begin{tabular}{|c|c|c|c|c|c|c|c|}
\hline & Percentil & $\mathrm{F} 1$ & $\mathrm{~F} 2$ & F3 & F4 & F5 & F6 \\
\hline & 80 & 24 & 4 & 18 & 17 & 45 & 10 \\
\hline \multirow[t]{2}{*}{ Cuartil 3} & 75 & 22 & 4 & 15 & 15 & 44 & 9 \\
\hline & 60 & 15 & 3 & 11 & 11 & 41 & 8 \\
\hline \multirow[t]{2}{*}{ Cuartil 2} & 50 & 13 & 2 & 9 & 9 & 39 & 7 \\
\hline & 40 & 10 & 2 & 7 & 6 & 38 & 6 \\
\hline \multirow[t]{2}{*}{ Cuartil 1} & 25 & 7 & 1 & 5 & 5 & 33 & 4 \\
\hline & 20 & 6 & 1 & 4 & 4 & 31 & 4 \\
\hline
\end{tabular}

\section{Tabla 16. Varones de 15 a 18 años}

\section{Factores ADA}

F1: Depresión-ansiedad

F2: Disocial con comportamiento adictivo

F3: Desregulación disruptiva del estado de ánimo comportamiento disocial

F4: Ansiedad social

F5: Resiliencia-prosocialidad

F6: Obsesión-compulsión

$\begin{array}{ccc}\text { N } & \text { M } & \text { DE } \\ 104 & 11.11 & 9.40 \\ 106 & 2.64 & 2.46 \\ 106 & 11.59 & 7.53 \\ 106 & 9.31 & 6.74 \\ 105 & 38.39 & 6.30 \\ 106 & 7.25 & 3.40\end{array}$

\section{Tabla 17. Chicas de 12 a 14 años}

\begin{tabular}{cccccccc} 
& Percentil & $F 1$ & $F 2$ & $F 3$ & $F 4$ & $F 5$ & $F 6$ \\
& 80 & 23 & 4 & 16 & 15 & 46 & 11 \\
\hline Cuartil 3 & 75 & 18.5 & 3 & 14 & 13 & 45 & 10 \\
\hline & 60 & -12 & 2 & -10 & 10 & 41 & 8 \\
\hline Cuartil 2 & 50 & 9 & 2 & 8 & 8 & 39 & 7 \\
\hline & 40 & 7.4 & 1 & 6 & 6 & --------- & 6 \\
\hline Cuartil 1 & 25 & 4 & 0 & 3 & 4 & 33 & 5 \\
\hline & 20 & 4 & 0 & 3 & 4 & 31 & 4 \\
\hline
\end{tabular}

-------- Media del factor.

\section{Tabla 19. Varones de 12 a 14 años}

\begin{tabular}{cccccccc} 
& Percentil & $F 1$ & $F 2$ & $F 3$ & $F 4$ & $F 5$ & $F 6$ \\
\hline \multirow{2}{*}{ Cuartil 3 } & 75 & 21.6 & 4 & 15 & 14 & 45 & 10 \\
\hline & 16.5 & 3 & 13 & 12 & 44 & 10 \\
\hline Cuartil 2 & 50 & -10.2 & 2 & 9 & 8 & 41 & 8 \\
\hline & 40 & 5 & 1 & 6 & 4 & --37 & 6 \\
\hline Cuartil 1 & 25 & 3 & 0 & 3 & 3 & 34 & 4 \\
\hline & 20 & 3 & 0 & 3 & 2 & 32 & 4 \\
\hline
\end{tabular}

--------- Media del factor. 
Tabla 20. Varones de 15 a 18 años

\begin{tabular}{|c|c|c|c|c|c|c|c|}
\hline & Percentil & F1 & F2 & F3 & F4 & F5 & F6 \\
\hline & 80 & 18 & 4 & 16.6 & 14 & 44 & 10 \\
\hline \multirow[t]{2}{*}{ Cuartil 3} & 75 & 15.75 & 4 & 16 & 12.25 & 43 & 9 \\
\hline & 60 & 11 & 3 & 12 & 9 & 40.6 & 8 \\
\hline \multirow[t]{2}{*}{ Cuartil 2} & 50 & 8 & 2 & 10 & 8 & 39 & 7 \\
\hline & 40 & 7 & 1.8 & 9 & 7 & 38 & 6 \\
\hline \multirow[t]{2}{*}{ Cuartil 1} & 25 & 4 & 1 & 7 & 5 & 35 & 5 \\
\hline & 20 & 3 & 0.4 & 5 & 4 & 34 & 4.4 \\
\hline
\end{tabular}

--------- Media del factor. 


\section{Bibliografía}

Aalsma, M. C., Lapsley, D. K., \& Flannery, D. J. (2006). Personal fables, narcissism, and adolescent adjustment. Psychology in the Schools, 43(4), 48-491. doi:10.1002/pits.20162

Achenbach, T. M. \& Edelbrock, C. (1978). The classification of child psychopathology: a review and analysis of empirical efforts. Psychological Bulletin, 85(6), 1275-1301. doi:10.1037/0033 2909.85.6.1275

Achenbach, T. M. \& Edelbrock, C. S. (1987). Manual for the Youth Self Report and profile. Burlington: University of Vermont.

Achenbach, T. M. (1991). Integrative Guide to the 1991 CBCL/418, YSR, and TRF Profiles. Burlington: University of Vermont, Department of Psychiatry.

Achenbach, T. M. (1995). Empirically Based Assessment and Taxonomy: Applications to Clinical Research. Psychological Assessment, 7(3), 261-274. doi: 10.1037/1040-3590.7.3.261

Achenbach, T. M. (2009). The Achenbach system of empirically based assessment (ASEBA): Development, findings, theory, and applications. Burlington: University of Vermont, Research Center for Children, Youth, and Families.

Achenbach, T. M. (2011). Commentary: Definitely more than measurement error: But how should we understand and deal with informant discrepancies? Journal of Clinical Child and Adolescent Psy chology, 40, 80-86.

Achenbach, T. M. (2020). Bottom-Up and Top-Down Paradigms for Psychopathology: A Half-Century Odyssey. Annual Review of Clinical Psychology, 16, 1-24. doi: https://doi.org/10.1146/annurev-clinpsy-071119-115831

Achenbach, T. M., Dumenci, L. \& Rescorla, L. A. (2002). Ten-year comparisons of problems and competencies for national samples of youth: self, parent, and teacher reports. Journal of Emotional and Behavioural Disorders, 4, 215-228. doi: 10.1177/10634266020100040101

Achenbach, T. M., Ivanova M. Y., Rescorla L. A., Turner, L. V., Turner M. A., \& Althoff, R. R. (2016) Internalizing/Externalizing Problems: Review and Recommendations for Clinical and Research Applications. Journal of the American Academy of Child \& Adolescent Psychiatry, 55 (8), 647-656. 
Achenbach, T. M., McConaughy, S. H., \& Howell, C. T. (1987). Child/adolescent behavioural and emotional problems: Implications of cross-informant correlations for situational specificity. Psychological Bulletin, 101(2), 213-232. doi: http://dx.doi.org/10.1037/0033-2909.101.2.213

Alfaro, J., Guzmán, J., García, C., Sirlopú, D., Reyes, F., \& Varela, J. (2016). Psychometric Properties of the Spanish Version of the Personal Wellbeing Index-School Children (PWI-SC) in Chilean School Children. Child Indicators Research, 9, 731-742. doi: 10.1007/s12187-015-9342-2

American Psychiatric Association. (2002). Manual Diagnóstico y Estadístico de los trastornos mentales, DSMIV-TR. Barcelona: Masson.

American Psychiatric Association. (2013). Diagnostic and Statistical Manual of Mental Disorders (5th ed.). Arlington: American Psychiatric Publishing.

Beck, F. \& Legleye, S. (2003). Evolutions récentes des usages de drogues à 17 ans: Escapad 2000-2002 Tendances, 29, 1-4.

Belloch, A. (2012). Propuestas para un enfoque transdiagnóstico de los trastornos mentales y del comportamiento: evidencia, utilidad y limitaciones. Revista de Psicopatología y Psicología Clinica, 17(3), 295-311.

Belloch, A., \& Álvarez, H. (2002). Trastornos de la personalidad. Madrid: Editorial Síntesis.

Belloch, A., Sandín, B. \& Ramos, F. (2009). Manual de Psicopatología (Vol. 1-2). Madrid: McGraw-Hill.

Berk, L. E. (2006). Development through the Lifespan (4th ed.). Illinois: Pearson.

Birhanu, A., Bisetengn, T. A., \& Woldeyohannes, S. M. (2014). High prevalence of substance use and associated factors among high school adolescents in Woreta Town, Northwest Ethiopia: multi-domain factor analysis. BMC Public Health, 14, 1186. doi: 10.1186/1471-2458-14-1186

Bogart, L. M., Collins, R. L., Ellickson, P. L., \& Klein, D. J. (2007). Are adolescent substance users less satisfied with life as young adults and if so, why? Social Indicators Research, 81, 149-169. doi: 10.1007/s11205-006-0019-6

Bordin, I. A., Rocha, M. M., Cristiane S. P., Teixeira, M. C., Achenbach, T. M., Rescorla, L. A., \& Silvares, E. F. M. (2013). Child Behaviour Checklist (CBCL), Youth Self-Report (YSR) and Teacher's Report Form (TRF): an overview of the development of the original and Brazilian versions. Cadernos de Saúde Pública, 29(1), 13-28. doi: 10.1590/s0102-311×2013000100004

Brann, E., Chaplin, J., Agelii, M., Sjoberg, A., Nikalsson, A., Albertsoon-Wikland, K., \& Lissner, L. (2017). Declining well-being in young Swedes born in 1990 versus 1974. Journal of Adolescent Health, 60, 306-312. doi: 10.1016/j.jadohealth.2016.10.009

Cajigas de Segredo, N., Kahan, E., Luzardo, M., Najson, S., Ugo, M. C. \& Zamalvide, G. (2004). Validación de la escala de agresión entre pares (bullying) en una muestra montevideana de adolescentes de ciclo básico. En VII Jornadas de Psicología Universitaria (pp. 452-457). Montevideo: Psicolibros.

Carretero-Dios, H. \& Pérez, C. (2005). Normas para el desarrollo y revisión de estudios instrumentales. International Journal of Clinical and Health Psychology, 5(3), 521-551.

Carretero-Dios, H. \& Pérez, C. (2007). Standards for the development and review of instrumental studies: considerations about test selection in psychological research. International Journal of Clinical and Health Psychology, 7(3), 863-882.
Casas, F. (2011). Subjective Social indicators and child and adolescent well-being. Child Indicators Research, 4, 555-575. doi: 10.1007/s12187-010-9093-z

Casas, F., Alfaro, J., Sarriera, J. C., Bedin, L., Grigoras, B., Bălțătescu, S., Malo, S. \& Sirlopú, D. (2015). El bienestar subjetivo en la infancia: Estudio de la comparabilidad de 3 escalas psicométricas en 4 países de habla latina. Psicoperspectivas, 14(1), 6-18. doi: 10.5027/psicoperspectivas-Vol14-Issue1-fulltext-522

Casas, F., Castella, J., Abs, D., Coenders, G., Alfaro, J., Saforcada, E., \& Tonon, G. (2012). Subjective indicators of personal well-being among adolescents. Performance and results for different scales in Latin-language speaking countries: a contribution to the international debate. Child Indicators Research, 5, 1-28. doi: 10.1007/s12187-011-9119-1

Casas, F., Figuer, C., Gonzalez, M., Malo, S., Alsinet, C., \& Subarroca, S. (2007). The well-being of 12 to 16 years old adolescents and their parents from 1999 to 2003 Spanish samples. Social Indicators Research, 83, 87-115. doi: 10.1007/s11205-006-9059-1

Caspi, A., Houts, R. M., Belsky, D. W., Goldman-Mellor, S. J., Harrington, H., Israel, S., Moffitt, T. E. (2013). The p factor: One general psychopathology factor in the structure of psychiatric disorders? Clinical Psychological Science, 2, 119-137. doi: 10.1177/2167702613497473

Castella-Sarriera, J., Saforcada, E., Tonon, G., Rodríguez de la Vega, R., Mozobancyk, S., \& Bedin, L. (2012). Bienestar Subjetivo de los Adolescentes: un estudio comparativo entre Argentina y Brasil. Psychosocial Intervention, 21(3), 273-280. doi: 10.5093/in2012a24.

Chavira, D. A., Stein, M. B., Bailey, K. \& Stein, M. T. (2004). Child anxiety in primary care: Prevalent but untreated. Depression and Anxiety, 20, 155-164. doi: 10.1002/da.20039

Contini, N., Coronel, P., Levin, M., \& Estevez, A. (2003). Estrategias de afrontamiento y bienestar psicológico en adolescentes escolarizados de Tucumán. Revista de Psicología, 21(1), 179-200. doi: https://doi.org/10.18800/psico.200301.007

Costa-Ball, D., González-Tornaría, M., del Arca, D., Mas- Juan, N. \& Olson, D. H. (2013). Propiedades Psicométricas del FACES IV: Estudio de validez en población uruguaya. Ciencias Psicológicas, 7(2): 119-132. doi: $10.22235 /$ cp.v7i1.1053

Costello, E. J. (2016). Early detection and prevention of mental health problems: developmental epidemiology and systems of support. Journal of Clinical Child and Adolescent Psychology, 45(6), 710717. doi: $10.1080 / 15374416.2016 .1236728$

Costello, E. J., Copeland, W. \& Angold, A. (2011). Trends in psychopathology across the adolescent years: what changes when children become adolescents, and when adolescents become adults? The Journal of Child Psychology and Psychiatry, 52(10), 1015-1025. doi: 10.1111/j.1469-7610.2011. 02446x

Costello, E. J., Mustillo, S, Erkanli, A, Keeler, G. \& Angold, A. (2003). Prevalence and development of psychiatric disorders in childhood and adolescence. Archives of General Psychiatry, 60(8), 837-44. doi: 10.1001/archpsyc.60.8.837

Crick, N. R. (1996). The Role of Overt Aggression, Relational Aggression, and Prosocial Behaviour in the Prediction of Children's Future Social Adjustment. Child Development, 67 (5), 2317-2327. 
Cummins, R. \& Lau, A. (2003). Community Integration or Community Exposure? A Review and Discussion in Relation to People with an Intellectual Disability. British Institute of Learning Disabilities, 16(2), 145-157. doi:10.1046/j.1468-3148.2003. 00157.x

Cummins, R. A. (2010). Subjective wellbeing, homeostatically protected mood and depression: a synthesis. Journal of Happiness Studies, 11, 1-17. doi 10.1007.

Cummins, R. A., Eckersley, R., Pallant, J., Van Vugt, J., \& Misajon, R. (2003). Developing a national index of subjective wellbeing: The Australian unity well-being Index. Social Indicators Research, 64, 159-190. doi: 10.1023/ A:1024704320683.

Cummins, R., Li, N., Wooden, M., \& Stokes, M. (2014). A demonstration of set- points for subjective well-being. Journal of Happiness Studies, 15, 183-206. doi: 10.1007/s10902-013-9444-9

Cutuli, J. J., Gillham, J. E., Chaplin, T. M., Reivich, K. J., Seligman, M. E. P., Gallop, R. J., Abenavoli, R. M. \& Freres, D. R. (2013). Preventing adolescents' externalizing and internalizing symptoms: Effects of the Penn Resiliency Program. International Journal of Emotional Education, 5(2), 67-79.

Daset, L. R. (2002). Depresión en la Adolescencia: una aproximación desde la evaluación empírica. Prisma, 18, 25-32.

Daset, L. R. (2005). Psicopatología en la Adolescencia: Relación entre aspectos psicopatológicos, variables sociodemográficas y competencias en una población de jóvenes uruguayos (Tesis doctoral). Murcia: Universidad de Murcia.

Daset, L. R., Fernández-Pintos, M. E., Costa-Ball, D., López-Soler, C., \& Vanderplasschen, W. (2015). Desarrollo instrumental del autoinforme de adolescentes (ADA). Ciencias Psicológicas, 9(1), 85104. doi: $10.22235 /$ cp.v9i1.169

Daset, L. R., López Soler, C., Hidalgo, M. D. (2009). Síndromes empíricos en una población adolescente evaluados mediante el YSR. Ciencias Psicológicas, 3(1), 67-82. doi: 10.22235/cp.v3i1.138

Diener, E., Lucas, R., Scollon, C. (2006). Beyond the hedonic treadmill. Revising the adaptation theory of well-being. American Psychological Association, 61(4), 305-314. doi: 10.1037/0003-066X.61.4.305

Diener, E., Oishi S., Lucas, R. E. (2003). Personality, Culture, and Subjective Well-Being: Emotional and Cognitive Evaluations of Life. Annual Review of Psychology, 54, 403-425. doi: 10.1146/annurev. psych.54.101601.145056

Echeburúa, E., De Corral, P. (2010). Adicción a las nuevas tecnologías y a las redes sociales en jóvenes: un nuevo reto. Adicciones, 22(2), 91-96. doi: 10.20882/adicciones.196

Elosua, P., Zumbo, B. (2008). Coeficientes de fiabilidad para escalas de respuesta categórica ordenada. Psicothema, 20(4), 896-901.

Evers A, Muñiz J., Hagemeister, C., Høstmælingen A., Lindley P., Sjöberg A., Bartram D. (2013). Assessing the quality of tests: Revision of the EFPA review model. Psicothema, 25(3), 283-291. doi: 10.7334/psicothema2013.97

Evers, A. (2012). The Internationalization of Test Reviewing: Trends, differences and results. International Journal of Testing, 12, 136-156. doi: 10.1080/15305058.2012.658932

Ferdinand, R. F. \& Verhulst, F. C. (1995). Psychopathology from adolescence into young adulthood: an 8-year follow-up study. American Journal of Psychiatry. doi: 10.1176/ajp.152.11.1586.
Fergusson, D. M., Boden, J. M., \& Horwood, L. I. (2013). Alcohol misuse and psychosocial outcomes in young adulthood: results from a longitudinal birth cohort studied to age 30. Drug and Alcohol Dependence, 133(2), 513-519. doi: 10.1016/j.drugalcdep.2013.07.015.

Fernández, M. E. \& Daset, L. R. (junio, 2019). Perfil de bienestar psicológico de adolescentes escolarizados uruguayos. En XXVI Congreso Internacional de Psicología INFAD. Universidad de Salamanca, España.

Fernández, M. E. \& Daset, L. R. (noviembre, 2019). Perfil de Bienestar Psicológico en adolescentes uruguayos. En XI Congreso Internacional de Investigación y Práctica Profesional en Psicología. Universidad de Buenos Aires, Argentina.

Fernández, M. E., Daset, L. R. \& Castelluccio, L. (2019). Perfil de bienestar psicológico subjetivo en adolescentes uruguayos. Suma Psicológica, 26(2), 103-109. doi: http://dx.doi.org/10.14349/sumapsi.2019.v26.n2.6

Fernández, M. E., Daset, L. R. \& Vanderplasschen, W. (mayo, 2015). Risk and protective factors in alcohol and marihuana using adolescents in Montevideo (Uruguay). En $9^{\text {th }}$ Annual Conference of the International Society for the Study of Drug Policy, Ghent, Bélgica. doi: 10.1108/DAT-01-2016-0002

Fernández, M. E., Van Damme, L., Daset, L. R. \& Vanderplasschen, W. (2020). Predictors of Domain-Specific Aspects of Subjective WellBeing among School Going Adolescents in Uruguay. Avances en Psicología Latinoamericana, 38(1), 85-99. doi: http://dx.doi.org/10.12804/revistas.urosario.

Ferrando, J., \& Anguiano-Carrasco, C. (2010). El análisis factorial como técnica de investigación. Papeles de Psicólogo, 31(1), 18-33.

Field, A. (2009). Discovering statistics using SPSS (3th ed.). Londres: Sage.

Flora, D. B. \& Curran, P. J. (2004). An empirical evaluation of alternative methods of estimation for confirmatory factor analysis with ordinal data. Psychological Methods, 9(4), 466-491. doi: /10.1037/1082-989X.9.4.466

Garcia, D., Sagone, E., De Caroli, M., \& Nima, A. (2017). Italian and Swedish adolescents: differences and associations in subjective well-being and psychological wellbeing. Peer J, 5, 26868. doi: $10.7717 /$ peerj. 2868

Gómez Bustamante, E., \& Cogollo, Z. (2010). Factores predictores relacionados con el bienestar general en adolescentes estudiantes de Cartagena, Colombia. Revista Salud Pública, 12(1), 61-70. doi: $10.15446 /$ rsap

González-Carrasco M., Casas, F., Malo, S., Vinas, F., \& Dinisman, T. (2017). Changes with age in subjective well-being through adolescent years: differences by gender. Journal of Happiness Studies, 18, 63-88. doi: 10.1007/s1090.

Gonzalez-Carrasco, M., Casas, F., Vinas, F., Malo, S., Gras, M., \& Bedin, L. (2017). What leads subjective well-being to change throughout adolescence? An exploration of potential factors. Child Indicators Research, 10, 33-56. doi: 10.1007/s12187-015-9359-6

Goodman R., Ford T., Richards H., Gatward R., Metzer, H. (2000). The development and well-being assessment: description and initial validation of an integrated assessment of child and adolescent psychopathology. Journal of Child Psychology and Psychiatry, 41, 645-655. 
Goodman, A., \& Goodman, R. (2009). Strengths and difficulties questionnaire as a dimensional measure of child mental health. Journal of the American Academy of Child and Adolescent Psychiatry, 48(4), 400-403.

Goodman, A., Lamping, D., Ploubidis, G. B. (2010). When to Use Broader Internalizing and Externalizing Subscales Instead of the Hypothesized Five Subscales on the Strengths and Difficulties Questionnaire (SDQ): Data from British Parents, Teachers and Children. Journal of Abnormal Child Psychology, 38(8). 1179-1191. doi: 10.1007/s10802-010-9434-x

Goodman, R. (1997). The Strengths and Difficulties Questionnaire: a research note. Journal of Child Psychology and Psychiatry, 38(5), 581-586.

Goodman, R. (1999). The extended version of the Strengths and Difficulties Questionnaire as a guide to child psychiatric caseness and consequent burden. Journal of Child Psychology and Psychiatry, 40(5), 791-799.

Goodman, R. (2001). Psychometric properties of the strengths and difficulties questionnaire. Journal of the American Academy of Child and Adolescent Psychiatry, 40(11), 1337-1345

Goodman, R. (2010). Substance use and common child mental health problems: examining longitudinal associations in a British simple. Addiction, 105, 1484-1496. doi: 10.1111/j.1360-0443.2010. 02981.x

Goodman, R., \& Scott, S. (1999). Comparing the Strengths and Difficulties Questionnaire and the Child Behavior Checklist: is small beautiful? Journal of Abnormal Child Psychology, 27(1), 17-24.

Goodman, R., Ford, T., Richards, H., Gatward, R., \& Meltzer, H. (2000). The Development and Well-Being Assessment: description and initial validation of an integrated assessment of child and adolescent psychopathology. Journal of Child Psychology and Psychiatry, 41(5), 645-655.

Goodman, R., Meltzer, H. \& Bailey, V. (1998) The strengths and difficulties questionnaire: A pilot study on the validity of the self-report version. European Child \& Adolescent Psychiatry, 7, 125-130. doi: https://doi.org/10.1007/s007870050057

Goodman, R., Renfrew, D. \& Mullick, M. (2000). Predicting type of psychiatric disorder from Strengths and Difficulties Questionnaire (SDQ) scores in child mental health clinics in London and Dhaka European Child \& Adolescent Psychiatry, 9, 129-124. doi: 10.1007/s007870050008

Hemphill, S., Heerde, J., Scholes-Balog, K., Herrenkohl, T., Toumbourou, J., \& Catalano, R. (2014) Effects of early adolescent alcohol use on mid-adolescent school performance and connection: A longitudinal study of students in Victoria, Australia and Washington State, United States. Journal of School Health, 84(11). doi: 10.1111/josh.12201

Horn, J. L. (1965). A rationale and test for the number of factors in factor-analysis. Psychometrika, 30(2), 179-185. doi: 10.1007/BF02289447

Huebner, S., Suldo, S., Smith, L., \& McKnigth, C. (2004). Life satisfaction in children and youth: Empirical foundations and implications for school psychologists. Psychology in the Schools, 41(1), 81-93. doi: $10.1002 /$ pits.10140

Hughes, C. (2017). Perfil de bienestar y psicopatológico de una población adolescente de contexto crítico (Tesis de grado). Montevideo: Universidad Católica del Uruguay.
Hunsley, J. \& Mash, E. J. (2005). Introduction to the special section on developing guidelines for the evidence-based assessment (EBA) of adult disorders. Psychological Assessment, 17, 251-255. doi: 10.1037/1040-3590.17.3.251

IBM Corporation. (2012). IBM SPSS Statistics 21. Recuperado de http://www-01.ibm.com/software/es/ analytics/spss/

Janssens, A. \& Deboutte, D. (2009). Screening for psychopathology in child welfare: the Strengths and Difficulties Questionnaire (SDQ) compared with the Achenbach System of Empirically Based Assessment (ASEBA). European Child and Adolescent Psychiatry, 18, 691-700. doi: 10.1007/ s00787-009-0030

Jordan, P., Rescorla, L. A., Althoff, R. R. \& Achenbach, T. M. (2016). International Comparisons of the Youth Self-Report Dysregulation Profile: Latent Class Analyses in 34 Societies. Journa of the American Academy of Child \& Adolescent Psychiatry, 55(12), 1046-1053. doi: https://doi. org/10.1016/j.jaac.2016.08.012

Junta Nacional de Drogas \& Observatorio Uruguayo de Drogas. (2011). Sobre ruidos y nueces. Consumo de drogas legales e ilegales en la adolescencia. Montevideo: Junta Nacional de Drogas \& Observatorio Uruguayo de Drogas.

Junta Nacional de Drogas \& Observatorio Uruguayo de Drogas. (2016). VI Encuesta nacional sobre consumo de drogas en estudiantes de enseñanza media, 2014. Informe de Investigación. Montevideo: Facultad de Humanidades y Ciencias de la Educación, Universidad de la República.

Junta Nacional de Drogas. (2012). 5ta. Encuesta nacional en hogares sobre consumo de drogas: informe de investigación. Montevideo: Junta Nacional de Drogas.

Keyes, C. (2006). Mental Health in adolescence: is America's youth flourishing? American Journal of Orthopsychiatry, 76(3), 395-402. doi: 10.1037/0002-9432.76.3.395

Kline, R. B. (2005). Principles and Practice of Structural Equation Modelling (2nd ed.). New York: The Guilford Press.

Laceulle, O. M., Vollebergh, W. A. M. \& Ormel, J. (2015). The Structure of Psychopathology in Adolescence: Replication of a General Psychopathology Factor in the Trails Study. Clinical Psychological Science, 1-11. doi: 10.1037/abn0000193

Legleye, S., Choquet M., Beck, F., Hassler, C., Spilka S., Morin, D. (2003). Les substances psychoactives chez les collégiens et lycéens: consommations en 2003 et évolutions depuis dix ans. Tendances, $35,1-6$.

Lemos, S. (2003). La psicopatología de la infancia y la adolescencia: consideraciones básicas para su estudio. Papeles del Psicólogo, 24(85), 19-28.

Lemos, S., Fidalgo, Á. M., Calvo, P., Menéndez, P. (1992). Salud mental de los adolescentes asturianos. Psicothema, 4(1), 21-48.

Liang, W., \& Chikritzhs, T. (2015). Age at first use of alcohol predicts the risk of heavy alcohol use in early adulthood: a longitudinal study in the United States. International Journal of Drug Policy, 26, 131-134. doi: 10.1016/j.drugpo.2014.07.001 
Livacic-Rojas, P., Vallejo, G., \& Fernández, P. (2006). Procedimientos estadísticos alternativos para evaluar la robustez mediante diseños de medidas repetidas. Revista Latinoamericana de Psicología, 38(3), 579-598.

Llambí, C. \& Piñeiro, L. (2012). Índice de nivel socioeconómico (INSE). Revisión anual, 2012. Montevideo: Centro de Investigaciones Económicas (Cinve), Uruguay.

Lloret-Segura, S., Ferreres-Traver, A., \& Tomás-Marco, A. H. I. (2014). El análisis factorial exploratorio de los ítems: una guía práctica, revisada y actualizada Introducción Determinación de la adecuación del Análisis. Anales de Psicología, 30(3), 1151-1169. doi: 10.6018/analesps.30.3.199361

López Soler, C., Fernández, M. V., Castro Sáez, M., Alcántara, M. V. \& López-Pina, J. A. (2009). Estructura factorial, comorbilidad y prevalencia del síndrome empírico problemas de pensamiento en una muestra pediátrica. Annuary of Clinical and Health Psychology, 5, 57-65.

López-Soler, C., García Montalvo, C., Pérez López, J., Brito, A., Tejerína, M. Y. \& Fernández-Ros, E. (1998). Psicopatología en la adolescencia: Taxonomías empíricas, rasgos de personalidad y estrés. (Proyecto HUM96/46). Murcia, Programa Séneca del Plan Regional de Investigación, Desarrollo Tecnológico y del Conocimiento.

Lorenzo-Seva, U. (1999a). Promin: A Method for Oblique Factor Rotation. Multivariate Behavioural Research, 34(3), 347-365. doi: 10.1207/S15327906MBR3403_3

Lorenzo-Seva, U., \& Ferrando, P. J. (2006). FACTOR: a computer program to fit the exploratory factor analysis model. Behaviour Research Methods, 38(1), 88-91. doi: 10.3758/BF03192753

Lozano, L. M., García-Cueto, E. \& Muñiz, J. (2008). Effect of the number of response categories on the reliability and validity of rating scales. Methodology, 4, 73-79. doi: 10.1027/1614-2241.4.2.73

Lyubomirsky, S., King, L. \& Dienner, E. (2005). The Benefits of Frequent Positive Affect: Does Happiness Lead to Success? Psychological Bulletin, 131(6), 803-855. doi: 10.1037/0033-2909.131.6.803

Mardia, K. V. (1970). Measures of Multivariate Skewness and Kurtosis with Principal Components. Biometrika, 57(3), 519-530. doi: 10.2307/2334770

Matsunaga, M. (2010). How to Factor-Analyze Your Data Right: Do's, Don'ts, and How-To's. International Journal of Psychological Research, 3(1), 97-110. doi: 10.21500/20112084.854

Maydeu-Olivares, A., Morera, O. \& D'Zurilla, T. J. (1999). Using Graphical Methods in Assessing Measurement Invariance in Inventory Data. Multivariate Behavioral Research, 34(3), 397-420. doi: https://doi.org/10.1207/S15327906MBR3403_5

McCallum, M., \& Goodman, S. H. (2019). A multimethod, multi-informant investigation of maternal validation and invalidation of female adolescents who engage in self-inflicted injury. Journal of Consulting and Clinical Psychology, 87(6), 563-575. https://doi.org/10.1037/ccp0000411

Meehl, P. E. (2001). Comorbidity and taximetrics. Clinical Psychology. Science and Practice, 8, 507-519. doi: 10.1093/clipsy/8.4.507

Meehl, P. E. (2004). What's in a Taxon? Journal of Abnormal Psychology, 113, 39-43. doi: 10.1037/0021843X.113.1.39

Mels, C. \& Trias, D. (2014). Características preliminares del HSCL-A adaptado para adolescentes uruguayos en contexto de violencia. Ciencias Psicológicas, 8(2) 139-149. doi: 10.22235/cp.v8i2.1032.
Montserrat, C., Dinisman, T., Baltatescu, S., Grigoras, B., \& Casas, F. (2015). The effect of critical changes and gender on adolescent's subjective well-being: comparisons across 8 countries. Child Indicators Research, 8, 11-131. doi: 10.1007/s12187-014-9288-9

Muñiz, J., Elosua, P. \& Hambleton, R. (2013). Directrices para la traducción y adaptación de los tests: segunda edición. Psicothema, 25(2), 151-157. doi: 10.7334/psicothema2013.24

Muthén, B., \& Kaplan D. (1985). A comparison of some methodologies for the factor analysis of non-normal Likert variables. British Journal of Mathematical and Statistical Psychology, 38, 171-189.

Muthén, B., \& Kaplan, D. (1992). A comparison of some methodologies for the factor analysis of non-normal Likert variables: A note on the size of the model. British Journal of Mathematical and Statistical Psychology, 45, 19-30. doi: 10.1111/j.2044-8317.1985.tb00832.x

Muthén, B., Du Toit, S. H. \& Spisic, D. (1997). Robust inference using weighted least squares and quadratic estimating equations in latent variable modelling with categorical and continuous outcomes. Psychometrika, 75, 1-45.

Muthén, L. K. \& Muthén, B. O. (1998-2007). Mplus User's Guide (5 ${ }^{\text {th }}$ ed). Los Ángeles: Muthén \& Muthén. Nelson, E. C., Hanna, G. L., Hudziak, J. J., Botteron, K. N., Heath, A. C., \& Todd, R. D. (2001). Obsessive-compulsive scale of the child behavior checklist: specificity, sensitivity, and predictive power. Pediatrics, 108(1), e-14. https://doi.org/10.1542/peds.108.1.e14

Noble, T. \& McGrath, H. (2014). Well-being and Resilience in School Settings. En G. Fava \& C. Ruini (Eds.), Increasing Psychological Well-being in Clinical and Educational Settings. Cross-Cultural Advancements in Positive Psychology (Vol. 8, pp. 135-152). doi: https://doi.org/10.1007/97894-017-8669-0_9

Nunnally, J. C. \& Bernstein, I. H. (1994). Psychometric theory (3 ${ }^{\text {rd }}$ Ed.). New York: McGraw-Hill.

Organización Mundial de la Salud \& Organización Panamericana de la Salud. (2009). Epidemiología de los Trastornos Mentales en América Latina y el Caribe. Washington: Organización Panamericana de la Salud.

Organización Mundial de la Salud. (1992). CIE 10. Trastornos Mentales y del Comportamiento: descripciones clinicas y pautas para el diagnóstico. Madrid: Meditor.

Palacios Delgado, J., \& Cañas Martínez, J. (2010). Características psicosociales asociadas al consumo de alcohol, tabaco y drogas en adolescentes de Chiapas. Psicología Iberoamericana, 18(2), 27-36.

Park, N. (2004). The Role of Subjective Well-Being in Positive Youth Development. The ANNALS of the American Academy of Political and Social Science, 591(1), 25-39. doi: 10.1177/0002716203260078

Peirano, N. (2013). Evaluación de la Resiliencia: una revisión sistemática sobre las técnicas de mayor uso (Tesis de grado). Montevideo: Universidad Católica del Uruguay.

Pérez Algorta, G. (2001). Taxonomías derivadas empíricamente de adolescentes de un instituto educativo privado (Tesis de grado). Montevideo: Universidad Católica del Uruguay.

Pérez, E., \& Medrano, L. (2010). Análisis Factorial Exploratorio: Bases Conceptuales y Metodológicas. Revista Argentina de Ciencias del Comportamiento, 2(1), 58-66. doi: 10.30882/1852. 4206. v2.n1.15924 
Proctor, E., Landsverk, J., Aarons, G., Chambers, D., Glisson, C. \& Mittman, B. (2009). Implementation Research in Mental Health Services: an Emerging Science with Conceptual, Methodological, and Training challenges. Administration and Policy in Mental Health and Mental Health Services Research, 36(1), 24-34. doi: 10.1007/s10488-008-0197-4

Quay, H. C. (1977). Measuring dimensions of deviant behaviour: The Behaviour Problem Checklist. Journal of Abnormal Child Psychology, 5(3), 277-287. doi: https://doi.org/10.1007/BF00913698

Rescorla, L. A, Achenbach, T. M., Ivanova, M. Y., Harder, V. S., Otten, L., Bilenberg, N, ... Verhulst, F. C. (2011). International comparisons of behavioural and emotional problems in preschool children: parents' reports from 24 societies. Journal of Clinical Child and Adolescent Psychology, 40(3), 456-467. doi: 10.1080/15374416.2011.563472

Rescorla, L. A., Achenbach, T. M., Ivanova, M. Y., Dumenci, L., Almqvist, F., Bilenberg, N., ... Verhulst, F. (2007). Epidemiological comparisons of problems and positive qualities reported by adolescents in 24 countries. Journal of Consulting and Clinical Psychology, 75(2), 351-358.

Rescorla, L. A., Ginzburg, S., Achenbach, T. M., Ivanova, M. Y., Almqvist, F., Begovac, I. ... Verhulst, F. C. (2013). Cross-informant agreement between parent-reported and adolescent self-reported problems in 25 societies. Journal of Clinical Child and Adolescent Psychology, 42(2), 262-73. doi: $10.1080 / 15374416.2012 .717870$

Richter, J., Sagatun, A., Heyerdahl, S., Oppedal, B., Roysamb, E. (2011). The Strengths and Difficulties Questionnaire (SDQ) - self-report. An analysis of its structure in a multi-ethnic urban adolescent sample. Journal of Child Psychology and Psychiatry, 52, 1002-1011. doi: 10.1111/j.14697610.2011.02372.x.

Rodríguez, M. N., \& Ruíz-Díaz, M. A. (2008). Atenuación de la asimetría y de la curtosis de las puntuaciones observadas mediante transformaciones de variables: Incidencia sobre la estructura factorial. Psicológica, 29(2), 205-227.

Roy A. K., Lopes, V. \& Klein, R. G. (2014). Disruptive Mood Dysregulation Disorder: A New Diagnostic Approach to Chronic Irritability in Youth. American Journal of Psychiatry, 171(9), 918-924. doi: 10.1176/appi.ajp.2014.13101301.

Rutter, M. (1997). Comorbidity: concepts, claims and choices. Criminal Behaviour and Mental Health, 7, 265-285. doi: 10.1002/cbm.190

Rutter, M. (2016). Why is the topic of the biological embedding of experiences important for translation? Development and Psychopathology, 28(2), 1245-1258. doi: 10.1017/S0954579416000821

Rutter, M., Giller, H. \& Hagell, A. (2000). La conducta antisocial de los jóvenes. Madrid: Cambridge University Press.

Ryff, C., Love, G., Miyamoto, Y., Markus, H., Curhan, K., Kitayama, S., Park, J., Kwakami, N., Kan, C., \& Karasawa, M. (2014). Culture and the promotion of wellbeing in East and West: Understanding varieties of attunement to the surrounding context. En Fava \& Ruini (eds.). Increasing Psychological well-being in Clinical and Educational Settings. Interventions and Cultural Contexts (pp. 1-19).

Sánchez Meca, J., Rosa Alcaráz, A. I. \& López Soler, C. (2011). The psychological treatment of sexual abuse in children and adolescents meta-analysis. International Journal of Clinical and Health Psychology, 11 (1), 67-79.
Santos de Pacual, A., Saura Garre, P. \& López Soler, C. (2020). Mental health in people with substance use disorder: differential aspects between men and women. Anales de psicología, 6(3), 443-45.

Schmitt T. A. (2011). Current methodological considerations in exploratory and confirmatory factor analysis. Journal of Psychoeducational Assessment, 29, 304-321. doi: 10.1177/0734282911406653

Schreiber, J., Nora, A., Stage, F., Barlow, E., \& King, J. (2006). Reporting Structural Equation Modelling and Confirmatory Factor Analysis Results: A Review. Journal of Educational Research, 99(6), 323337. doi:10.3200/JOER.99.6.323-338

Seagrave, D., \& Grisso, T. (2002). Adolescent development and the measurement of juvenile psychopathy. Law and Human Behaviour, 26(2), 219-239. doi: 10.1023/A:1014696110850

Steinberg, L. (2001). We know same things: Parent-adolescent relationships in retrospect and prospect. Journal of Research Adolescence, 11(1), 1-19. doi: 10.1111/1532-7795.00001

Suldo, S., \& Huebner, S. (2004). Does life satisfaction moderate the effects of stressful life events on psychopathological behaviour during adolescence? School Psychology Quarterly, 19(2), 93-105. doi https://doi.org/10.1521/scpq.19.2.93.33313

Thapar, A., Pine, D. S., Leckman, J. F., Scott, S., Snowling, M. J., \& Taylor, E. A. (2015). Rutter's Child and Adolescent Psychiatry, (6 ${ }^{\text {th }}$ ed.). Oxford: Wiley-Blackwell.

The International Well-Being Group. (2013). Personal Well-Being Index, English Manual (5 ${ }^{\text {th }}$ ed.). The Australian Centre on Quality of Life, Deakin University.

Thurber, S. \& Sheehan, W. (2012). Note on truncated T scores in discrepancy studies with the Child Behavior Checklist and Youth Self Report. Archives of Assessment Psychology, 2(1), 73-80.

Timmerman, M. E. \& Lorenzo-Seva, U. (2011). Dimensionality assessment of ordered polytomous items with parallel analysis. Psychological Methods, 16(2), 209-220. doi.org/10.1037/a0023353

Tomyn, A. \& Cummins, R. (2011). Subjective wellbeing and homeostatically protected mood: Theroy validation with adolescents. Journal of Happiness Studies, 12(5), 894-914. doi: 10.1007/s10902 010-9235-5.

Tomyn, A., Weinber, M., \& Cummins, R. (2015). Intervention efficacy among "at risk" adolescents: A test of subjective well-being homeostasis theory. Social Indicators Research, 120, 883-895. doi: 10.1007/s11205-014-0619-5

Van der Ende, J., Verhulst, F. C., \& Tiemeier, H. (2012). Agreement of informants on emotional and behavioral problems from childhood to adulthood. Psychological Assessment, 24, 293-300. doi 10.1037/a0025500

Van Ouytsel, J., Ponnet, K., \& Walrave, M. (2017). The associations of adolescent's dating violence victimization, well-being and engagement in risk behaviours. Journal of Adolescence, 55, 66-71. doi: 10.1016/j.adolescence.2016.12.005

Vanderplasschen, W., Bloor, M., McKeganey, N. (2010). Long-Term Outcomes of Aftercare Participation following Various Forms of Drug Abuse Treatment in Scotland. Journal of Drug Issues, 40(3), 703-728. doi: 10.1177/002204261004000308 
Vandevelde, S., Laenen, F. V., Van Damme, L., Vanderplasschen, W., Audenaert, K., Broekaert, E., \& Vander Beken, T. (2017). Dilemmas in applying strengths-based approaches in working with offenders with mental illness: A critical multidisciplinary review. Aggression and Violent Behaviour, 32, 71-79. doi: https://doi.org/10.1016/j.avb.2016.11.008

Veerman J. W. \& De Meyer, R. (2012). Ten-Year Time Trends in Emotional and Behavioural Problems of Dutch Children Referred for Youth Care. Journal of Emotional and Behavioural Disorders, 20(3), 184-192. doi: $10.1177 / 1063426611417626$

Verhulst, F. C., Achenbach, T. M., Van der Ende,J., Erol, N., Lambert, M. C., Leung, P.,...Zubrick, S. R. (2003). Comparisons of problems reportedly youths from seven countries. The American Journal of Psychiatry, 160(8), 1479-1485.

Viola, L., Garrido, G. \& Varela, A. (2008). Estudio Epidemiológico de la Salud Mental de los Niños Uruguayos. Montevideo: GEGA.

Wagnild, G. M. \& Young, H. M. (1993). Development and psychometric evaluation of the Resilience Scale. Journal of Nursing Measurement, 1, 165-178.

Williams, B., Brown, T., \& Onsman, A. (2010). Exploratory factor analysis: A five-step guide for novices. Austral-Asian Journal of Paramedicine, 8(3). doi: 10.33151/ajp.8.3.93

Wongtongkam, N., Ward, P., Day, A., Winefield, A. (2014). The influence of protective and risk factor in individual, peer and school domains on Tai adolescent's alcohol and illicit drug use: A survey. Addictive Behaviours, 39, 1447-1451. doi: 10.1016/j.addbeh.2014.05.026

Youngstrom, E. A. (2013). Future directions in psychological assessment: combining evidence-based medicine innovations with psychology's historical strengths to enhance utility. Journal of Clinical Child Adolescent Psychology, 42(1), 139-59. doi: 10.1080/15374416.2012.736358

Zullig, K., Valois, R., Huebner, S., Oeltmann, J., \& Drane, W. (2001). Relationship between Perceived Life Satisfaction and Adolescents' Substance Abuse. Journal of Adolescent Health, 29, 279-288. doi: 10.1016/S1054-139X(01)00269-5 
ANEXOS 
Anexo 1
Baremos 


\section{Baremos}

Calculo de factores:

F1

$\mathrm{ADA} 1+\mathrm{ADA} 2+\mathrm{ADA} 4+\mathrm{ADA} 5+\mathrm{ADA} 10+\mathrm{ADA} 11+\mathrm{ADA} 22+\mathrm{ADA} 27+\mathrm{ADA} 29+\mathrm{ADA} 30+\mathrm{A}-$ DA31+ADA32+ADA38+ADA42+ADA46+ADA47+ADA50+ADA53+ADA56+A DA66+ADA76+ADA80

F2

ADA13+ADA15+ADA16+ADA18+ADA20+ADA57

F3

ADA14+ADA17+ADA34+ADA36+ADA37+ADA43+ADA44+ADA45+ADA48+ADA55+ADA60+ADA64+ADA67+ADA73+ADA75+ADA77+ADA79

F4

ADA7+ADA9+ADA19+ADA21+ADA33+ADA51+ADA52+ADA53+ADA54+ADA59+ADA62+ADA68+ADA69+ADA78

F5

ADA6+ADA23+ADA25+ADA26+ADA28+ADA35+ADA39+ADA41+ADA49+ADA61+ADA63+ADA65+ADA70+ADA74

F6

ADA24+ADA40+ADA70+ADA81+ADA82

Los puntos de cuartiles son los siguientes: 


\section{$Q 1=$ percentil 25; $Q 2=$ percentil 50; $Q 3=$ percentil 75}

Los últimos percentiles hasta el 100 no aparecen porque tiene los mismos valores que el último percentil que figura en la tabla.

Tabla 21. Baremos para chicas de 12 a 14 años

$\mathrm{N}=688$

\begin{tabular}{|c|c|c|c|c|c|c|}
\hline Percentiles & $\mathrm{F} 1$ & F2 & F3 & F4 & F5 & F6 \\
\hline 95 & 40.4000 & 6.0000 & 25.3000 & 25.3000 & 52.0000 & 14.0000 \\
\hline 94 & 38.4400 & 5.6000 & 25.0000 & 24.0000 & 52.0000 & 14.0000 \\
\hline 93 & 36.0000 & 5.0000 & 24.6200 & 23.2400 & 51.8300 & 14.0000 \\
\hline 92 & 35.0000 & 5.0000 & 23.2800 & 21.2800 & 50.5200 & 13.0000 \\
\hline 91 & 33.6600 & 5.0000 & 21.0000 & 21.0000 & 50.0000 & 13.0000 \\
\hline 90 & 32.4000 & 5.0000 & 20.6000 & 21.0000 & 50.0000 & 13.0000 \\
\hline 89 & 31.1400 & 5.0000 & 20.0000 & 20.0000 & 49.5900 & 12.0000 \\
\hline 88 & 29.8800 & 5.0000 & 19.0000 & 19.9200 & 48.0000 & 12.0000 \\
\hline 87 & 27.6200 & 5.0000 & 18.5800 & 19.0000 & 48.0000 & 12.0000 \\
\hline 86 & 27.0000 & 4.0000 & 18.0000 & 18.0000 & 48.0000 & 12.0000 \\
\hline 85 & 26.0000 & 4.0000 & 18.0000 & 18.0000 & 47.0000 & 11.0000 \\
\hline 84 & 25.8400 & 4.0000 & 18.0000 & 17.0000 & 47.0000 & 11.0000 \\
\hline 83 & 25.0000 & 4.0000 & 17.0000 & 17.0000 & 47.0000 & 11.0000 \\
\hline 82 & 25.0000 & 4.0000 & 16.0000 & 16.0000 & 46.0000 & 11.0000 \\
\hline 81 & 24.0000 & 4.0000 & 16.0000 & 16.0000 & 46.0000 & 11.0000 \\
\hline 80 & 23.0000 & 4.0000 & 16.0000 & 15.0000 & 46.0000 & 11.0000 \\
\hline 79 & 22.0000 & 4.0000 & 15.0000 & 14.0000 & 46.0000 & 11.0000 \\
\hline 78 & 21.0000 & 3.0000 & 14.5200 & 14.0000 & 46.0000 & 10.2000 \\
\hline 77 & 21.0000 & 3.0000 & 14.0000 & 14.0000 & 45.8700 & 10.0000 \\
\hline 76 & 20.0000 & 3.0000 & 14.0000 & 13.0000 & 45.0000 & 10.0000 \\
\hline 75 & 18.5000 & 3.0000 & 14.0000 & 13.0000 & 45.0000 & 10.0000 \\
\hline 74 & 18.0000 & 3.0000 & 14.0000 & 13.0000 & 45.0000 & 10.0000 \\
\hline 73 & 17.0000 & 3.0000 & 13.0000 & 13.0000 & 44.6300 & 9.2000 \\
\hline 72 & 17.0000 & 3.0000 & 13.0000 & 13.0000 & 44.0000 & 9.0000 \\
\hline 71 & 16.0000 & 3.0000 & 13.0000 & 13.0000 & 44.0000 & 9.0000 \\
\hline 70 & 16.0000 & 3.0000 & 13.0000 & 12.8000 & 44.0000 & 9.0000 \\
\hline 69 & 16.0000 & 3.0000 & 13.0000 & 12.0000 & 44.0000 & 9.0000 \\
\hline 68 & 15.6800 & 3.0000 & 12.0000 & 12.0000 & 44.0000 & 9.0000 \\
\hline 67 & 15.0000 & 2.8000 & 12.0000 & 11.0000 & 43.0000 & 9.0000 \\
\hline 66 & 15.0000 & 2.0000 & 12.0000 & 11.0000 & 43.0000 & 9.0000 \\
\hline 65 & 14.0000 & 2.0000 & 11.1000 & 11.0000 & 43.0000 & 9.0000 \\
\hline 64 & 14.0000 & 2.0000 & 11.0000 & 10.0000 & 42.8400 & 8.6000 \\
\hline 63 & 13.3800 & 2.0000 & 11.0000 & 10.0000 & 42.0000 & 8.0000 \\
\hline 62 & 13.0000 & 2.0000 & 11.0000 & 10.0000 & 42.0000 & 8.0000 \\
\hline 61 & 12.8600 & 2.0000 & 10.0000 & 10.0000 & 41.9100 & 8.0000 \\
\hline 60 & 12.0000 & 2.0000 & 10.0000 & 10.0000 & 41.0000 & 8.0000 \\
\hline
\end{tabular}

\begin{tabular}{|c|c|c|c|c|c|c|}
\hline Percentiles & F1 & F2 & F3 & F4 & F5 & F6 \\
\hline 59 & 12.0000 & 2.0000 & 9.0000 & 10.0000 & 41.0000 & 8.0000 \\
\hline 58 & 12.0000 & 2.0000 & 9.0000 & 9.0000 & 41.0000 & 8.0000 \\
\hline 57 & 12.0000 & 2.0000 & 9.0000 & 9.0000 & 41.0000 & 8.0000 \\
\hline 56 & 12.0000 & 2.0000 & 9.0000 & 9.0000 & 40.3600 & 8.0000 \\
\hline 55 & 11.0000 & 2.0000 & 9.0000 & 8.0000 & 40.0000 & 8.0000 \\
\hline 54 & 11.0000 & 2.0000 & 9.0000 & 8.0000 & 40.0000 & 7.6000 \\
\hline 53 & 10.0000 & 2.0000 & 8.0200 & 8.0000 & 40.0000 & 7.0000 \\
\hline 52 & 10.0000 & 2.0000 & 8.0000 & 8.0000 & 40.0000 & 7.0000 \\
\hline 51 & 10.0000 & 2.0000 & 8.0000 & 8.0000 & 40.0000 & 7.0000 \\
\hline 50 & 9.0000 & 2.0000 & 8.0000 & 8.0000 & 39.0000 & 7.0000 \\
\hline 49 & 9.0000 & 1.0000 & 8.0000 & 7.0000 & 39.0000 & 7.0000 \\
\hline 48 & 9.0000 & 1.0000 & 8.0000 & 7.0000 & 39.0000 & 7.0000 \\
\hline 47 & 9.0000 & 1.0000 & 8.0000 & 7.0000 & 39.0000 & 7.0000 \\
\hline 46 & 9.0000 & 1.0000 & 7.0000 & 7.0000 & 39.0000 & 7.0000 \\
\hline 45 & 8.0000 & 1.0000 & 7.0000 & 7.0000 & 39.0000 & 7.0000 \\
\hline 44 & 8.0000 & 1.0000 & 7.0000 & 7.0000 & 39.0000 & 6.6000 \\
\hline 43 & 8.0000 & 1.0000 & 7.0000 & 7.0000 & 38.0000 & 6.0000 \\
\hline 42 & 8.0000 & 1.0000 & 7.0000 & 7.0000 & 38.0000 & 6.0000 \\
\hline 41 & 8.0000 & 1.0000 & 6.0000 & 6.0000 & 38.0000 & 6.0000 \\
\hline 40 & 7.4000 & 1.0000 & 6.0000 & 6.0000 & 38.0000 & 6.0000 \\
\hline 39 & 7.0000 & 1.0000 & 5.2600 & 6.0000 & 38.0000 & 6.0000 \\
\hline 38 & 7.0000 & 1.0000 & 5.0000 & 6.0000 & 37.7800 & 6.0000 \\
\hline 37 & 7.0000 & 1.0000 & 5.0000 & 6.0000 & 37.0000 & 6.0000 \\
\hline 36 & 6.0000 & 1.0000 & 5.0000 & 6.0000 & 37.0000 & 6.0000 \\
\hline 35 & 6.0000 & 1.0000 & 4.0000 & 6.0000 & 36.8500 & 6.0000 \\
\hline 34 & 6.0000 & 1.0000 & 4.0000 & 6.0000 & 36.0000 & 6.0000 \\
\hline 33 & 6.0000 & 1.0000 & 4.0000 & 5.0000 & 36.0000 & 5.0000 \\
\hline 32 & 6.0000 & 1.0000 & 4.0000 & 5.0000 & 35.9200 & 5.0000 \\
\hline 31 & 5.0600 & 1.0000 & 4.0000 & 5.0000 & 35.0000 & 5.0000 \\
\hline 30 & 5.0000 & 0.0000 & 4.0000 & 5.0000 & 35.0000 & 5.0000 \\
\hline 29 & 5.0000 & 0.0000 & 4.0000 & 5.0000 & 34.0000 & 5.0000 \\
\hline 28 & 5.0000 & 0.0000 & 4.0000 & 5.0000 & 34.0000 & 5.0000 \\
\hline 27 & 4.0000 & 0.0000 & 3.1800 & 4.1800 & 33.0000 & 5.0000 \\
\hline 26 & 4.0000 & 0.0000 & 3.0000 & 4.0000 & 33.0000 & 5.0000 \\
\hline 25 & 4.0000 & 0.0000 & 3.0000 & 4.0000 & 33.0000 & 5.0000 \\
\hline 24 & 4.0000 & 0.0000 & 3.0000 & 4.0000 & 32.0000 & 5.0000 \\
\hline 23 & 4.0000 & 0.0000 & 3.0000 & 4.0000 & 32.0000 & 5.0000 \\
\hline 22 & 4.0000 & 0.0000 & 3.0000 & 4.0000 & 32.0000 & 4.8000 \\
\hline 21 & 4.0000 & 0.0000 & 3.0000 & 4.0000 & 31.0000 & 4.0000 \\
\hline 20 & 4.0000 & 0.0000 & 3.0000 & 4.0000 & 31.0000 & 4.0000 \\
\hline 19 & 3.0000 & 0.0000 & 3.0000 & 3.4600 & 30.8900 & 4.0000 \\
\hline 18 & 3.0000 & 0.0000 & 2.0000 & 3.0000 & 30.0000 & 4.0000 \\
\hline 17 & 3.0000 & 0.0000 & 2.0000 & 3.0000 & 30.0000 & 4.0000 \\
\hline 16 & 3.0000 & 0.0000 & 2.0000 & 3.0000 & 30.0000 & 4.0000 \\
\hline 15 & 3.0000 & 0.0000 & 2.0000 & 3.0000 & 29.6500 & 4.0000 \\
\hline 14 & 3.0000 & 0.0000 & 2.0000 & 2.7600 & 29.0000 & 4.0000 \\
\hline
\end{tabular}




\begin{tabular}{|ccccccc|}
\hline Percentiles & F1 & F2 & F3 & F4 & F5 & F6 \\
\hline 13 & 3.0000 & 0.0000 & 2.0000 & 2.0000 & 29.0000 & 3.2000 \\
\hline 12 & 2.1200 & 0.0000 & 2.0000 & 2.0000 & 28.7200 & 3.0000 \\
\hline 11 & 2.0000 & 0.0000 & 1.0000 & 2.0000 & 28.0000 & 3.0000 \\
\hline 10 & 2.0000 & 0.0000 & 1.0000 & 2.0000 & 27.1000 & 3.0000 \\
\hline 9 & 2.0000 & 0.0000 & 1.0000 & 2.0000 & 26.0000 & 2.6000 \\
\hline 8 & 2.0000 & 0.0000 & 1.0000 & 1.7200 & 25.0000 & 2.0000 \\
\hline 7 & 2.0000 & 0.0000 & 1.0000 & 1.0000 & 24.1700 & 2.0000 \\
\hline 6 & 1.5600 & 0.0000 & 1.0000 & 1.0000 & 22.8600 & 2.0000 \\
\hline 5 & 1.0000 & 0.0000 & 1.0000 & 1.0000 & 21.5500 & 2.0000 \\
\hline 4 & 1.0000 & 0.0000 & 0.0000 & 0.3600 & 21.0000 & 1.6000 \\
\hline 3 & 0.0000 & 0.0000 & 0.0000 & 0.0000 & 19.0000 & 1.0000 \\
\hline 2 & 0.0000 & 0.0000 & 0.0000 & 0.0000 & 18.0000 & 0.0000 \\
\hline 1 & 0.0000 & 0.0000 & 0.0000 & 0.0000 & 12.2400 & 0.0000 \\
\hline
\end{tabular}

\section{Tabla 22. Baremos para chicas de 15 a 18 años}

$\mathrm{N}=688$

\begin{tabular}{|ccccccc|}
\hline Percentiles & $F 1$ & $F 2$ & $F 3$ & $F 4$ & $F 5$ & $F 6$ \\
\hline 95 & 46.400 & 6.000 & 28.950 & 25.000 & 50.000 & 13.900 \\
\hline 94 & 44.440 & 6.000 & 26.620 & 25.000 & 49.480 & 13.000 \\
\hline 93 & 43.000 & 6.000 & 25.000 & 25.000 & 49.000 & 13.000 \\
\hline 92 & 40.960 & 6.000 & 24.720 & 24.000 & 49.000 & 12.000 \\
\hline 91 & 38.320 & 5.220 & 24.000 & 24.000 & 49.000 & 12.000 \\
\hline 90 & 33.600 & 5.000 & 23.900 & 23.000 & 48.000 & 12.000 \\
\hline 89 & 30.000 & 5.000 & 23.000 & 22.600 & 48.000 & 11.380 \\
\hline 88 & 30.000 & 5.000 & 23.000 & 20.400 & 47.960 & 11.000 \\
\hline 87 & 29.060 & 5.000 & 22.000 & 19.800 & 47.000 & 10.540 \\
\hline 86 & 28.680 & 5.000 & 21.260 & 19.000 & 47.000 & 10.000 \\
\hline 85 & 28.000 & 5.000 & 20.000 & 19.000 & 46.700 & 10.000 \\
\hline 84 & 27.000 & 5.000 & 20.000 & 19.000 & 46.000 & 10.000 \\
\hline 83 & 26.540 & 4.860 & 20.000 & 19.000 & 45.860 & 10.000 \\
\hline 82 & 25.160 & 4.000 & 19.620 & 18.000 & 45.000 & 10.000 \\
\hline 81 & 25.000 & 4.000 & 19.000 & 18.000 & 45.000 & 10.000 \\
\hline 80 & 24.400 & 4.000 & 18.800 & 17.000 & 45.000 & 10.000 \\
\hline 79 & 23.020 & 4.000 & 18.000 & 17.000 & 45.000 & 10.000 \\
\hline 78 & 23.000 & 4.000 & 16.980 & 16.200 & 44.000 & 9.000 \\
\hline 77 & 23.000 & 4.000 & 16.000 & 16.000 & 44.000 & 9.000 \\
\hline 76 & 22.000 & 4.000 & 15.160 & 15.400 & 44.000 & 9.000 \\
\hline 75 & 22.000 & 4.000 & 15.000 & 15.000 & 44.000 & 9.000 \\
\hline 74 & 21.120 & 4.000 & 15.000 & 14.600 & 44.000 & 9.000 \\
\hline 73 & 21.000 & 3.660 & 14.000 & 14.000 & 43.660 & 9.000 \\
\hline 72 & 21.000 & 3.000 & 14.000 & 14.000 & 43.000 & 9.000 \\
\hline 71 & 20.000 & 3.000 & 14.000 & 14.000 & 43.000 & 8.820 \\
\hline 70 & 20.000 & 3.000 & 14.000 & 14.000 & 43.000 & 8.000 \\
\hline
\end{tabular}

\begin{tabular}{|c|c|c|c|c|c|c|}
\hline Percentiles & F1 & F2 & F3 & F4 & F5 & F6 \\
\hline 69 & 19.220 & 3.000 & 14.000 & 14.000 & 43.000 & 8.000 \\
\hline 68 & 19.000 & 3.000 & 13.000 & 13.200 & 43.000 & 8.000 \\
\hline 67 & 18.460 & 3.000 & 13.000 & 13.000 & 43.000 & 8.000 \\
\hline 66 & 18.000 & 3.000 & 13.000 & 13.000 & 42.000 & 8.000 \\
\hline 65 & 18.000 & 3.000 & 13.000 & 13.000 & 42.000 & 8.000 \\
\hline 64 & 17.320 & 3.000 & 12.240 & 13.000 & 42.000 & 8.000 \\
\hline 63 & 16.940 & 3.000 & 12.000 & 13.000 & 42.000 & 8.000 \\
\hline 62 & 16.000 & 3.000 & 12.000 & 12.800 & 42.000 & 8.000 \\
\hline 61 & 15.180 & 3.000 & 12.000 & 12.000 & 41.000 & 8.000 \\
\hline 60 & 15.000 & 3.000 & 11.000 & 11.000 & 41.000 & 8.000 \\
\hline 59 & 14.420 & 3.000 & 11.000 & 11.000 & 41.000 & 7.000 \\
\hline 58 & 14.000 & 3.000 & 11.000 & 11.000 & 41.000 & 7.000 \\
\hline 57 & 14.000 & 3.000 & 11.000 & 11.000 & 41.000 & 7.000 \\
\hline 56 & 14.000 & 3.000 & 11.000 & 10.400 & 40.520 & 7.000 \\
\hline 55 & 13.000 & 3.000 & 10.550 & 10.000 & 40.000 & 7.000 \\
\hline 54 & 13.000 & 2.680 & 10.000 & 10.000 & 40.000 & 7.000 \\
\hline 53 & 13.000 & 2.000 & 10.000 & 10.000 & 40.000 & 7.000 \\
\hline 52 & 13.000 & 2.000 & 9.320 & 9.000 & 39.000 & 7.000 \\
\hline 51 & 13.000 & 2.000 & 9.000 & 9.000 & 39.000 & 7.000 \\
\hline 50 & 13.000 & 2.000 & 9.000 & 9.000 & 39.000 & 7.000 \\
\hline 49 & 12.620 & 2.000 & 9.000 & 8.600 & 39.000 & 7.000 \\
\hline 48 & 12.000 & 2.000 & 8.680 & 8.000 & 39.000 & 7.000 \\
\hline 47 & 12.000 & 2.000 & 8.000 & 7.800 & 39.000 & 7.000 \\
\hline 46 & 12.000 & 2.000 & 8.000 & 7.000 & 39.000 & 6.320 \\
\hline 45 & 11.100 & 2.000 & 7.450 & 7.000 & 38.900 & 6.000 \\
\hline 44 & 11.000 & 2.000 & 7.000 & 7.000 & 38.000 & 6.000 \\
\hline 43 & 11.000 & 2.000 & 7.000 & 7.000 & 38.000 & 6.000 \\
\hline 42 & 10.960 & 2.000 & 7.000 & 7.000 & 38.000 & 6.000 \\
\hline 41 & 10.000 & 2.000 & 7.000 & 6.400 & 38.000 & 6.000 \\
\hline 40 & 10.000 & 2.000 & 7.000 & 6.000 & 38.000 & 6.000 \\
\hline 39 & 10.000 & 2.000 & 7.000 & 6.000 & 37.380 & 6.000 \\
\hline 38 & 9.440 & 2.000 & 7.000 & 6.000 & 37.000 & 6.000 \\
\hline 37 & 9.000 & 2.000 & 7.000 & 6.000 & 37.000 & 6.000 \\
\hline 36 & 9.000 & 1.120 & 6.000 & 6.000 & 36.120 & 5.120 \\
\hline 35 & 9.000 & 1.000 & 6.000 & 6.000 & 36.000 & 5.000 \\
\hline 34 & 9.000 & 1.000 & 6.000 & 6.000 & 36.000 & 5.000 \\
\hline 33 & 8.540 & 1.000 & 6.000 & 5.200 & 35.000 & 5.000 \\
\hline 32 & 8.000 & 1.000 & 5.120 & 5.000 & 35.000 & 5.000 \\
\hline 31 & 8.000 & 1.000 & 5.000 & 5.000 & 35.000 & 5.000 \\
\hline 30 & 8.000 & 1.000 & 5.000 & 5.000 & 35.000 & 4.600 \\
\hline 29 & 8.000 & 1.000 & 5.000 & 5.000 & 35.000 & 4.000 \\
\hline 28 & 8.000 & 1.000 & 5.000 & 5.000 & 34.000 & 4.000 \\
\hline 27 & 7.260 & 1.000 & 5.000 & 5.000 & 34.000 & 4.000 \\
\hline 26 & 7.000 & 1.000 & 5.000 & 5.000 & 33.000 & 4.000 \\
\hline 25 & 7.000 & 1.000 & 5.000 & 5.000 & 33.000 & 4.000 \\
\hline 24 & 7.000 & 1.000 & 5.000 & 5.000 & 33.000 & 4.000 \\
\hline 23 & 6.000 & 1.000 & 4.430 & 4.200 & 32.000 & 4.000 \\
\hline 22 & 6.000 & 1.000 & 4.000 & 4.000 & 32.000 & 4.000 \\
\hline 21 & 6.000 & 1.000 & 4.000 & 4.000 & 31.820 & 4.000 \\
\hline
\end{tabular}




\begin{tabular}{|ccccccc|}
\hline Percentiles & $F 1$ & $F 2$ & $F 3$ & $F 4$ & $F 5$ & $F 6$ \\
\hline 20 & 6.000 & 1.000 & 4.000 & 4.000 & 31.000 & 4.000 \\
\hline 19 & 6.000 & 0.980 & 3.000 & 4.000 & 31.000 & 4.000 \\
\hline 18 & 5.000 & 0.000 & 3.000 & 4.000 & 31.000 & 4.000 \\
\hline 17 & 5.000 & 0.000 & 3.000 & 4.000 & 31.000 & 4.000 \\
\hline 16 & 5.000 & 0.000 & 3.000 & 4.000 & 30.720 & 3.720 \\
\hline 15 & 4.700 & 0.000 & 3.000 & 3.000 & 30.000 & 3.000 \\
\hline 14 & 4.000 & 0.000 & 2.740 & 3.000 & 30.000 & 3.000 \\
\hline 13 & 3.940 & 0.000 & 2.000 & 3.000 & 29.460 & 3.000 \\
\hline 12 & 3.000 & 0.000 & 2.000 & 3.000 & 28.040 & 3.000 \\
\hline 11 & 3.000 & 0.000 & 2.000 & 3.000 & 27.620 & 3.000 \\
\hline 10 & 2.800 & 0.000 & 2.000 & 3.000 & 27.000 & 3.000 \\
\hline 9 & 2.000 & 0.000 & 1.000 & 2.000 & 27.000 & 3.000 \\
\hline 8 & 2.000 & 0.000 & 1.000 & 2.000 & 27.000 & 2.360 \\
\hline 7 & 1.000 & 0.000 & 1.000 & 1.800 & 26.000 & 2.000 \\
\hline 6 & 1.000 & 0.000 & 1.000 & 1.000 & 24.560 & 2.000 \\
\hline 5 & 1.000 & 0.000 & 1.000 & 0.000 & 23.000 & 2.000 \\
\hline 4 & 1.000 & 0.000 & 0.000 & 0.000 & 21.680 & 1.680 \\
\hline 3 & 0.140 & 0.000 & 0.000 & 0.000 & 20.260 & 1.000 \\
\hline 2 & 0.000 & 0.000 & 0.000 & 0.000 & 14.520 & 0.000 \\
\hline 1 & 0.000 & 0.000 & 0.000 & 0.000 & 9.680 & 0.000 \\
\hline
\end{tabular}

\section{Tabla 23. Baremos para varones de 12 a 14 año}

\begin{tabular}{|ccccccc|}
\hline Percentiles & $F 1$ & $F 2$ & $F 3$ & $F 4$ & $F 5$ & $F 6$ \\
\hline 95 & 31.7500 & 7.000 & 26.0000 & 21.0000 & 48.4000 & 13.6500 \\
\hline 94 & 30.7000 & 7.000 & 26.0000 & 21.0000 & 47.0000 & 13.0000 \\
\hline 93 & 29.6500 & 7.000 & 25.0200 & 21.0000 & 46.5800 & 12.5100 \\
\hline 92 & 29.0000 & 6.440 & 23.4400 & 21.0000 & 46.0000 & 12.0000 \\
\hline 91 & 27.2000 & 6.000 & 22.3700 & 20.3700 & 45.4600 & 12.0000 \\
\hline 90 & 25.0000 & 6.000 & 20.6000 & 20.0000 & 45.0000 & 11.3000 \\
\hline 89 & 24.4500 & 6.000 & 20.0000 & 19.2300 & 45.0000 & 11.0000 \\
\hline 88 & 23.4000 & 5.160 & 20.0000 & 19.0000 & 45.0000 & 11.0000 \\
\hline 87 & 22.3500 & 5.000 & 20.0000 & 17.1800 & 45.0000 & 11.0000 \\
\hline 86 & 22.0000 & 5.000 & 19.0200 & 16.0200 & 45.0000 & 11.0000 \\
\hline 85 & 21.2500 & 5.000 & 18.0000 & 16.0000 & 45.0000 & 10.9500 \\
\hline 84 & 21.0000 & 5.000 & 17.8800 & 16.0000 & 44.0400 & 10.0000 \\
\hline 83 & 19.3000 & 5.000 & 17.0000 & 15.8100 & 44.0000 & 10.0000 \\
\hline 82 & 19.0000 & 4.740 & 17.0000 & 15.0000 & 44.0000 & 10.0000 \\
\hline 81 & 19.0000 & 4.000 & 17.0000 & 14.6700 & 44.0000 & 10.0000 \\
\hline 80 & 18.0000 & 4.000 & 16.6000 & 14.0000 & 44.0000 & 10.0000 \\
\hline 79 & 18.0000 & 4.000 & 16.0000 & 14.0000 & 44.0000 & 10.0000 \\
\hline 78 & 17.8000 & 4.000 & 16.0000 & 14.0000 & 43.6800 & 9.4600 \\
\hline 77 & 16.0000 & 4.000 & 16.0000 & 13.3900 & 43.0000 & 9.0000 \\
\hline 76 & 16.0000 & 4.000 & 16.0000 & 13.0000 & 43.0000 & 9.0000 \\
\hline 75 & 15.7500 & 4.000 & 16.0000 & 12.2500 & 43.0000 & 9.0000 \\
\hline
\end{tabular}

\begin{tabular}{|c|c|c|c|c|c|c|}
\hline Percentiles & $F 1$ & F2 & F3 & $F 4$ & F5 & F6 \\
\hline 74 & 15.0000 & 4.000 & 16.0000 & 12.0000 & 43.0000 & 9.0000 \\
\hline 73 & 14.6500 & 4.000 & 15.1100 & 12.0000 & 43.0000 & 9.0000 \\
\hline 72 & 14.0000 & 4.000 & 15.0000 & 12.0000 & 42.3200 & 9.0000 \\
\hline 71 & 13.5500 & 4.000 & 15.0000 & 12.0000 & 42.0000 & 9.0000 \\
\hline 70 & 13.0000 & 3.900 & 14.9000 & 12.0000 & 42.0000 & 9.0000 \\
\hline 69 & 13.0000 & 3.000 & 14.0000 & 11.8300 & 42.0000 & 9.0000 \\
\hline 68 & 13.0000 & 3.000 & 14.0000 & 11.0000 & 42.0000 & 9.0000 \\
\hline 67 & 13.0000 & 3.000 & 14.0000 & 11.0000 & 41.0200 & 9.0000 \\
\hline 66 & 13.0000 & 3.000 & 14.0000 & 11.0000 & 41.0000 & 8.6200 \\
\hline 65 & 12.2500 & 3.000 & 13.5500 & 11.0000 & 41.0000 & 8.0000 \\
\hline 64 & 12.0000 & 3.000 & 13.0000 & 10.4800 & 41.0000 & 8.0000 \\
\hline 63 & 12.0000 & 3.000 & 13.0000 & 10.0000 & 41.0000 & 8.0000 \\
\hline 62 & 12.0000 & 3.000 & 13.0000 & 9.3400 & 41.0000 & 8.0000 \\
\hline 61 & 12.0000 & 3.000 & 13.0000 & 9.0000 & 41.0000 & 8.0000 \\
\hline 60 & 11.0000 & 3.000 & 12.2000 & 9.0000 & 40.6000 & 8.0000 \\
\hline 59 & 10.9500 & 3.000 & 12.0000 & 9.0000 & 40.0000 & 8.0000 \\
\hline 58 & 10.0000 & 3.000 & 11.0600 & 9.0000 & 40.0000 & 8.0000 \\
\hline 57 & 10.0000 & 3.000 & 11.0000 & 9.0000 & 40.0000 & 8.0000 \\
\hline 56 & 9.8000 & 3.000 & 11.0000 & 9.0000 & 40.0000 & 8.0000 \\
\hline 55 & 9.0000 & 2.850 & 11.0000 & 9.0000 & 39.3000 & 8.0000 \\
\hline 54 & 9.0000 & 2.000 & 10.7800 & 8.7800 & 39.0000 & 8.0000 \\
\hline 53 & 9.0000 & 2.000 & 10.0000 & 8.0000 & 39.0000 & 8.0000 \\
\hline 52 & 8.6000 & 2.000 & 10.0000 & 8.0000 & 39.0000 & 7.6400 \\
\hline 51 & 8.0000 & 2.000 & 10.0000 & 8.0000 & 39.0000 & 7.0000 \\
\hline 50 & 8.0000 & 2.000 & 10.0000 & 8.0000 & 39.0000 & 7.0000 \\
\hline 49 & 7.4500 & 2.000 & 10.0000 & 8.0000 & 39.0000 & 7.0000 \\
\hline 48 & 7.0000 & 2.000 & 10.0000 & 7.3600 & 39.0000 & 7.0000 \\
\hline 47 & 7.0000 & 2.000 & 10.0000 & 7.0000 & 38.8200 & 7.0000 \\
\hline 46 & 7.0000 & 2.000 & 10.0000 & 7.0000 & 38.0000 & 7.0000 \\
\hline 45 & 7.0000 & 2.000 & 10.0000 & 7.0000 & 38.0000 & 7.0000 \\
\hline 44 & 7.0000 & 2.000 & 10.0000 & 7.0000 & 38.0000 & 7.0000 \\
\hline 43 & 7.0000 & 2.000 & 9.0100 & 7.0000 & 38.0000 & 7.0000 \\
\hline 42 & 7.0000 & 2.000 & 9.0000 & 7.0000 & 38.0000 & 6.0000 \\
\hline 41 & 7.0000 & 2.000 & 9.0000 & 7.0000 & 38.0000 & 6.0000 \\
\hline 40 & 7.0000 & 1.800 & 9.0000 & 7.0000 & 38.0000 & 6.0000 \\
\hline 39 & 6.0000 & 1.000 & 9.0000 & 7.0000 & 38.0000 & 6.0000 \\
\hline 38 & 6.0000 & 1.000 & 9.0000 & 6.6600 & 37.2800 & 6.0000 \\
\hline 37 & 6.0000 & 1.000 & 8.5900 & 6.0000 & 37.0000 & 6.0000 \\
\hline 36 & 6.0000 & 1.000 & 8.0000 & 6.0000 & 37.0000 & 6.0000 \\
\hline 35 & 5.7500 & 1.000 & 8.0000 & 6.0000 & 37.0000 & 6.0000 \\
\hline 34 & 5.0000 & 1.000 & 8.0000 & 6.0000 & 37.0000 & 6.0000 \\
\hline 33 & 5.0000 & 1.000 & 7.3100 & 6.0000 & 36.9800 & 6.0000 \\
\hline 32 & 5.0000 & 1.000 & 7.0000 & 6.0000 & 36.0000 & 5.2400 \\
\hline 31 & 5.0000 & 1.000 & 7.0000 & 6.0000 & 36.0000 & 5.0000 \\
\hline 30 & 5.0000 & 1.000 & 7.0000 & 6.0000 & 36.0000 & 5.0000 \\
\hline 29 & 5.0000 & 1.000 & 7.0000 & 5.0300 & 36.0000 & 5.0000 \\
\hline
\end{tabular}




\begin{tabular}{|ccccccc|}
\hline Percentiles & $F 1$ & $F 2$ & $F 3$ & $F 4$ & $F 5$ & $F 6$ \\
\hline 28 & 4.4000 & 1.000 & 7.0000 & 5.0000 & 35.6800 & 5.0000 \\
\hline 27 & 4.0000 & 1.000 & 7.0000 & 5.0000 & 35.0000 & 5.0000 \\
\hline 26 & 4.0000 & 1.000 & 7.0000 & 5.0000 & 35.0000 & 5.0000 \\
\hline 25 & 4.0000 & 1.000 & 7.0000 & 5.0000 & 35.0000 & 5.0000 \\
\hline 24 & 4.0000 & 1.000 & 7.0000 & 5.0000 & 35.0000 & 5.0000 \\
\hline 23 & 4.0000 & 1.000 & 7.0000 & 5.0000 & 34.3800 & 5.0000 \\
\hline 22 & 4.0000 & 1.000 & 6.5400 & 4.5400 & 34.0000 & 5.0000 \\
\hline 21 & 4.0000 & 1.000 & 5.4700 & 4.0000 & 34.0000 & 5.0000 \\
\hline 20 & 3.0000 & 0.400 & 5.0000 & 4.0000 & 34.0000 & 4.4000 \\
\hline 19 & 3.0000 & 0.000 & 5.0000 & 4.0000 & 33.1400 & 4.0000 \\
\hline 18 & 3.0000 & 0.000 & 5.0000 & 4.0000 & 33.0000 & 4.0000 \\
\hline 17 & 3.0000 & 0.000 & 5.0000 & 3.1900 & 32.0200 & 4.0000 \\
\hline 16 & 3.0000 & 0.000 & 5.0000 & 3.0000 & 31.9600 & 4.0000 \\
\hline 15 & 3.0000 & 0.000 & 3.1000 & 3.0000 & 31.0000 & 4.0000 \\
\hline 14 & 3.0000 & 0.000 & 3.0000 & 2.0000 & 31.0000 & 3.0000 \\
\hline 13 & 2.6500 & 0.000 & 3.0000 & 2.0000 & 30.7800 & 3.0000 \\
\hline 12 & 2.0000 & 0.000 & 3.0000 & 2.0000 & 30.0000 & 3.0000 \\
\hline 11 & 2.0000 & 0.000 & 3.0000 & 1.7700 & 30.0000 & 3.0000 \\
\hline 10 & 2.0000 & 0.000 & 2.7000 & 1.0000 & 29.6000 & 3.0000 \\
\hline 9 & 1.4500 & 0.000 & 2.0000 & 1.0000 & 29.0000 & 2.6300 \\
\hline 8 & 1.0000 & 0.000 & 2.0000 & 1.0000 & 29.0000 & 2.0000 \\
\hline 7 & 1.0000 & 0.000 & 2.0000 & 1.0000 & 27.8400 & 2.0000 \\
\hline 6 & 1.0000 & 0.000 & 2.0000 & 0.4200 & 27.0000 & 2.0000 \\
\hline 5 & 1.0000 & 0.000 & 1.3500 & 0.0000 & 27.0000 & 2.0000 \\
\hline 4 & 1.0000 & 0.000 & 1.0000 & 0.0000 & 24.7200 & 2.0000 \\
\hline 3 & 0.1500 & 0.000 & 1.0000 & 0.0000 & 23.1800 & 1.2100 \\
\hline 2 & - & 0.000 & 1.0000 & 0.0000 & 22.1200 & 1.0000 \\
\hline 1 & - & 0.000 & 1.0000 & 0.0000 & 2.1200 & 0.0700 \\
\hline & & & & & & \\
\hline
\end{tabular}

Tabla 24. Baremos para varones de 15 a 18 años

$\mathrm{N}=688$

\begin{tabular}{|ccccccc|}
\hline Percentiles & $F 1$ & $F 2$ & $F 3$ & $F 4$ & $F 5$ & $F 6$ \\
\hline 95 & 31.7500 & 7.0000 & 26.0000 & 21.0000 & 48.4000 & 13.6500 \\
\hline 94 & 30.7000 & 7.0000 & 26.0000 & 21.0000 & 47.0000 & 13.0000 \\
\hline 93 & 29.6500 & 7.0000 & 25.0200 & 21.0000 & 46.5800 & 12.5100 \\
\hline 92 & 29.0000 & 6.4400 & 23.4400 & 21.0000 & 46.0000 & 12.0000 \\
\hline 91 & 27.2000 & 6.0000 & 22.3700 & 20.3700 & 45.4600 & 12.0000 \\
\hline 90 & 25.0000 & 6.0000 & 20.6000 & 20.0000 & 45.0000 & 11.3000 \\
\hline 89 & 24.4500 & 6.0000 & 20.0000 & 19.2300 & 45.0000 & 11.0000 \\
\hline 88 & 23.4000 & 5.1600 & 20.0000 & 19.0000 & 45.0000 & 11.0000 \\
\hline 87 & 22.3500 & 5.0000 & 20.0000 & 17.1800 & 45.0000 & 11.0000 \\
\hline 86 & 22.0000 & 5.0000 & 19.0200 & 16.0200 & 45.0000 & 11.0000 \\
\hline
\end{tabular}

\begin{tabular}{|c|c|c|c|c|c|c|}
\hline Percentiles & $\mathrm{F} 1$ & F2 & F3 & $\mathrm{F} 4$ & F5 & F6 \\
\hline 85 & 21.2500 & 5.0000 & 18.0000 & 16.0000 & 45.0000 & 10.9500 \\
\hline 84 & 21.0000 & 5.0000 & 17.8800 & 16.0000 & 44.0400 & 10.0000 \\
\hline 83 & 19.3000 & 5.0000 & 17.0000 & 15.8100 & 44.0000 & 10.0000 \\
\hline 82 & 19.0000 & 4.7400 & 17.0000 & 15.0000 & 44.0000 & 10.0000 \\
\hline 81 & 19.0000 & 4.0000 & 17.0000 & 14.6700 & 44.0000 & 10.0000 \\
\hline 80 & 18.0000 & 4.0000 & 16.6000 & 14.0000 & 44.0000 & 10.0000 \\
\hline 79 & 18.0000 & 4.0000 & 16.0000 & 14.0000 & 44.0000 & 10.0000 \\
\hline 78 & 17.8000 & 4.0000 & 16.0000 & 14.0000 & 43.6800 & 9.4600 \\
\hline 77 & 16.0000 & 4.0000 & 16.0000 & 13.3900 & 43.0000 & 9.0000 \\
\hline 76 & 16.0000 & 4.0000 & 16.0000 & 13.0000 & 43.0000 & 9.0000 \\
\hline 75 & 15.7500 & 4.0000 & 16.0000 & 12.2500 & 43.0000 & 9.0000 \\
\hline 74 & 15.0000 & 4.0000 & 16.0000 & 12.0000 & 43.0000 & 9.0000 \\
\hline 73 & 14.6500 & 4.0000 & 15.1100 & 12.0000 & 43.0000 & 9.0000 \\
\hline 72 & 14.0000 & 4.0000 & 15.0000 & 12.0000 & 42.3200 & 9.0000 \\
\hline 71 & 13.5500 & 4.0000 & 15.0000 & 12.0000 & 42.0000 & 9.0000 \\
\hline 70 & 13.0000 & 3.9000 & 14.9000 & 12.0000 & 42.0000 & 9.0000 \\
\hline 69 & 13.0000 & 3.0000 & 14.0000 & 11.8300 & 42.0000 & 9.0000 \\
\hline 68 & 13.0000 & 3.0000 & 14.0000 & 11.0000 & 42.0000 & 9.0000 \\
\hline 67 & 13.0000 & 3.0000 & 14.0000 & 11.0000 & 41.0200 & 9.0000 \\
\hline 66 & 13.0000 & 3.0000 & 14.0000 & 11.0000 & 41.0000 & 8.6200 \\
\hline 65 & 12.2500 & 3.0000 & 13.5500 & 11.0000 & 41.0000 & 8.0000 \\
\hline 64 & 12.0000 & 3.0000 & 13.0000 & 10.4800 & 41.0000 & 8.0000 \\
\hline 63 & 12.0000 & 3.0000 & 13.0000 & 10.0000 & 41.0000 & 8.0000 \\
\hline 62 & 12.0000 & 3.0000 & 13.0000 & 9.3400 & 41.0000 & 8.0000 \\
\hline 61 & 12.0000 & 3.0000 & 13.0000 & 9.0000 & 41.0000 & 8.0000 \\
\hline 60 & 11.0000 & 3.0000 & 12.2000 & 9.0000 & 40.6000 & 8.0000 \\
\hline 59 & 10.9500 & 3.0000 & 12.0000 & 9.0000 & 40.0000 & 8.0000 \\
\hline 58 & 10.0000 & 3.0000 & 11.0600 & 9.0000 & 40.0000 & 8.0000 \\
\hline 57 & 10.0000 & 3.0000 & 11.0000 & 9.0000 & 40.0000 & 8.0000 \\
\hline 56 & 9.8000 & 3.0000 & 11.0000 & 9.0000 & 40.0000 & 8.0000 \\
\hline 55 & 9.0000 & 2.8500 & 11.0000 & 9.0000 & 39.3000 & 8.0000 \\
\hline 54 & 9.0000 & 2.0000 & 10.7800 & 8.7800 & 39.0000 & 8.0000 \\
\hline 53 & 9.0000 & 2.0000 & 10.0000 & 8.0000 & 39.0000 & 8.0000 \\
\hline 52 & 8.6000 & 2.0000 & 10.0000 & 8.0000 & 39.0000 & 7.6400 \\
\hline 51 & 8.0000 & 2.0000 & 10.0000 & 8.0000 & 39.0000 & 7.0000 \\
\hline 50 & 8.0000 & 2.0000 & 10.0000 & 8.0000 & 39.0000 & 7.0000 \\
\hline 49 & 7.4500 & 2.0000 & 10.0000 & 8.0000 & 39.0000 & 7.0000 \\
\hline 48 & 7.0000 & 2.0000 & 10.0000 & 7.3600 & 39.0000 & 7.0000 \\
\hline 47 & 7.0000 & 2.0000 & 10.0000 & 7.0000 & 38.8200 & 7.0000 \\
\hline 46 & 7.0000 & 2.0000 & 10.0000 & 7.0000 & 38.0000 & 7.0000 \\
\hline 45 & 7.0000 & 2.0000 & 10.0000 & 7.0000 & 38.0000 & 7.0000 \\
\hline 44 & 7.0000 & 2.0000 & 10.0000 & 7.0000 & 38.0000 & 7.0000 \\
\hline 43 & 7.0000 & 2.0000 & 9.0100 & 7.0000 & 38.0000 & 7.0000 \\
\hline 42 & 7.0000 & 2.0000 & 9.0000 & 7.0000 & 38.0000 & 6.0000 \\
\hline 41 & 7.0000 & 2.0000 & 9.0000 & 7.0000 & 38.0000 & 6.0000 \\
\hline 40 & 7.0000 & 1.8800 & 9.0000 & 7.0000 & 38.0000 & 6.0000 \\
\hline
\end{tabular}




\begin{tabular}{|ccccccc|}
\hline Percentiles & $F 1$ & $F 2$ & $F 3$ & $F 4$ & $F 5$ & $F 6$ \\
\hline 39 & 6.0000 & 1.0000 & 9.0000 & 7.0000 & 38.0000 & 6.0000 \\
\hline 38 & 6.0000 & 1.0000 & 9.0000 & 6.6600 & 37.2800 & 6.0000 \\
\hline 37 & 6.0000 & 1.0000 & 8.5900 & 6.0000 & 37.0000 & 6.0000 \\
\hline 36 & 6.0000 & 1.0000 & 8.0000 & 6.0000 & 37.0000 & 6.0000 \\
\hline 35 & 5.7500 & 1.0000 & 8.0000 & 6.0000 & 37.0000 & 6.0000 \\
\hline 34 & 5.0000 & 1.0000 & 8.0000 & 6.0000 & 37.0000 & 6.0000 \\
\hline 33 & 5.0000 & 1.0000 & 7.3100 & 6.0000 & 36.9800 & 6.0000 \\
\hline 32 & 5.0000 & 1.0000 & 7.0000 & 6.0000 & 36.0000 & 5.2400 \\
\hline 31 & 5.0000 & 1.0000 & 7.0000 & 6.0000 & 36.0000 & 5.0000 \\
\hline 30 & 5.0000 & 1.0000 & 7.0000 & 6.0000 & 36.0000 & 5.0000 \\
\hline 29 & 5.0000 & 1.0000 & 7.0000 & 5.0300 & 36.0000 & 5.0000 \\
\hline 28 & 4.4000 & 1.0000 & 7.0000 & 5.0000 & 35.6800 & 5.0000 \\
\hline 27 & 4.0000 & 1.0000 & 7.0000 & 5.0000 & 35.0000 & 5.0000 \\
\hline 26 & 4.0000 & 1.0000 & 7.0000 & 5.0000 & 35.0000 & 5.0000 \\
\hline 25 & 4.0000 & 1.0000 & 7.0000 & 5.0000 & 35.0000 & 5.0000 \\
\hline 24 & 4.0000 & 1.0000 & 7.0000 & 5.0000 & 35.0000 & 5.0000 \\
\hline 23 & 4.0000 & 1.0000 & 7.0000 & 5.0000 & 34.3800 & 5.0000 \\
\hline 22 & 4.0000 & 1.0000 & 6.5400 & 4.5400 & 34.0000 & 5.0000 \\
\hline 21 & 4.0000 & 1.0000 & 5.4700 & 4.0000 & 34.0000 & 5.0000 \\
\hline 20 & 3.0000 & 0.4000 & 5.0000 & 4.0000 & 34.0000 & 4.4000 \\
\hline 19 & 3.0000 & 0.0000 & 5.0000 & 4.0000 & 33.1400 & 4.0000 \\
\hline 18 & 3.0000 & 0.0000 & 5.0000 & 4.0000 & 33.0000 & 4.0000 \\
\hline 17 & 3.0000 & 0.0000 & 5.0000 & 3.1900 & 32.0200 & 4.0000 \\
\hline 16 & 3.0000 & 0.0000 & 5.0000 & 3.0000 & 31.9600 & 4.0000 \\
\hline 15 & 3.0000 & 0.0000 & 3.1000 & 3.0000 & 31.0000 & 4.0000 \\
\hline 14 & 3.0000 & 0.0000 & 3.0000 & 2.0000 & 31.0000 & 3.0000 \\
\hline 13 & 2.6500 & 0.0000 & 3.0000 & 2.0000 & 30.7800 & 3.0000 \\
\hline 12 & 2.0000 & 0.0000 & 3.0000 & 2.0000 & 3.0000 & 3.0000 \\
\hline 11 & 2.0000 & 0.0000 & 3.0000 & 1.7700 & 30.0000 & 3.0000 \\
\hline 10 & 2.0000 & 0.0000 & 2.7000 & 1.0000 & 29.6000 & 3.0000 \\
\hline 9 & 1.4500 & 0.0000 & 2.0000 & 1.0000 & 29.0000 & 2.6300 \\
\hline 8 & 1.0000 & 0.0000 & 2.0000 & 1.0000 & 29.0000 & 2.0000 \\
\hline 7 & 1.0000 & 0.0000 & 2.0000 & 1.0000 & 27.8400 & 2.0000 \\
\hline 6 & 1.0000 & 0.0000 & 2.0000 & 0.4200 & 27.0000 & 2.0000 \\
\hline 5 & 1.0000 & 0.0000 & 1.3500 & 0.0000 & 27.0000 & 2.0000 \\
\hline 4 & 1.0000 & 0.0000 & 1.0000 & 0.0000 & 24.7200 & 2.0000 \\
\hline 3 & 0.1500 & 0.0000 & 1.0000 & 0.0000 & 23.1800 & 1.2100 \\
\hline 2 & 0.0000 & 0.0000 & 1.0000 & 0.0000 & 22.1200 & 1.0000 \\
\hline 1 & 0.0000 & 0.0000 & 1.0000 & 0.0000 & 20.1200 & 0.0700 \\
\hline & & & & & & \\
\hline
\end{tabular}


Anexo 2

Instrumentos

del Protocolo ADA 


\section{Encuesta sociodemográfica ADA}

A continuación, encontrarás una serie de preguntas para elegir una opción que te represente y en algún caso escribir una palabra o colocar un número. Es importante que respondas honestamente, ya que utilizaremos la información para ayudar a otros jóvenes como tú. Si bien debes colocar tu nombre, toda la información del cuestionario es confidencial.

1. Número que te han asignado:

2. Sexo:

$$
\begin{aligned}
& \square \text { Femenino } \\
& \square \text { Masculino }
\end{aligned}
$$

3. Género con el que te identificas:
Femenino
Masculino
$\square$ Prefiero no decirlo
Otro:

4. Crees tener ascendencia:

$\square$ Afro o negra
$\square$ Asiática o amarilla
$\square$ Blanca
$\square$ Indígena
$\square$ Otra:


5. Fecha de nacimiento:

6. Año que cursas:

7. País de nacimiento:

8. Departamento en el que vives:

9. Barrio en el que vives:

10. Cuál es la principal persona que sostiene económicamente el hogar:

$\square$ Madre
$\square$ Padre
$\square$ Hermano/a
$\square$ Tío/a
$\square$ Otra: (¿quién?)

11. ¿Cuál es el máximo nivel de estudios que completó esa persona?

$\square$ No tiene estudios
$\square$ Escuela (primaria)
$\square$ Liceo (secundaria)
$\square$ Enseñanza técnica (UTU o similar)
$\square$ Estudios terciarios (universidad, magisterio, profesorado)
$\square$ Estudios de posgrado

12. ¿Qué atención médica recibe el principal sostenedor del hogar?
Salud pública
$\square$ Seguro médico privado
$\square$ Mutualistas
Hospital Militar/Policial

13. ¿Tienen empleado/a que cumpla tareas domésticas?

$\square$ No
$\square$ Sí, por hora (viene algunos días)
$\square$ Sí, por día (viene todos los días)
$\square$ Sí, con cama (duerme en la casa)

\section{Acerca de tu casa}

14.1 ¿Hay auto en tu casa? Escribe la cantidad

14.2 ¿Hay TV en tu casa? Escribe la cantidad

14.3 ¿Hay heladera en tu casa? Escribe la cantidad

14.4 ¿Hay baño en tu casa? Escribe la cantidad

La totalidad de esta encuesta está disponible por solicitud a enlace mencionado en la web. 


\section{Cuestionario ADA versión extendida}

A continuación te presentamos una lista de frases. Lee con atención y contesta con sinceridad, no dejes ninguna pregunta en blanco. Responde en qué medida estás de acuerdo o lo que dice te representa. Marca con una cruz un solo casillero, según las siguientes opciones. Es importante que sepas que no hay respuestas buenas o malas.

\begin{tabular}{|c|c|}
\hline NADA de acuerdo & marca una cruz en el 0 \\
\hline MUY POCO de acuerdo & marca una cruz en el 1 \\
\hline POCO de acuerdo & marca una cruz en el 2 \\
\hline BASTANTE de acuerdo & marca una cruz en el 3 \\
\hline MUY de acuerdo & marca una cruz en el 4 \\
\hline
\end{tabular}

Algunos ejemplos de ítems:

- Aunque otras personas piensen que soy delgado/a, yo me veo gordo/a

- Me siento demasiado culpable por cosas que hago.

- Debo ser perfecto/a en todo lo que hago.

- Estar con otras personas me hace sentir bien.

- Si tengo ganas de romper algo, me cuesta controlarme. 


\section{Cuestionario ADA versión abreviada}

Tabla 25. Protocolo ADA abreviado (24 ítems)

$\begin{array}{lllllll} & \text { Nada } & \begin{array}{c}\text { Muy } \\ \text { poco }\end{array} & \text { Poco } & \text { Bastante } & \text { Muy } \\ \begin{array}{l}\text { 1. He robado cosas o dinero fuera de mi casa } \\ \text { 2. Hago sufrir animales si tengo ganas }\end{array} & 0 & 1 & 2 & 3 & 4 \\ \begin{array}{l}\text { 3. Cada vez necesito consumir más alcohol o } \\ \text { drogas para sentir el mismo efecto }\end{array} & 0 & 1 & 2 & 3 & 4 \\ \begin{array}{l}\text { 4. He prendido fuego cosas que no debía } \\ \text { 5. Pienso en cómo quitarme la vida }\end{array} & 0 & 1 & 2 & 3 & 4 \\ \text { 6. Me siento tan mal que quisiera hacerme daño } & 0 & 1 & 2 & 3 & 4\end{array}$

La totalidad de este cuestionario está disponible por solicitud a enlace mencionado en la web. 


\section{Anexo 3}

Consentimiento informado 


\section{Consentimiento informado}

El protocolo ADA se antecede de los correspondientes consentimientos informados, uno para los padres, tutores o responsables jurídicos de cada joven; otro para cada joven y un tercero para los casos de institucionalización, donde se requiere este aval.

Los datos solo podrán ser ingresados si se cumple con el requisito de completar y firmar el consentimiento informado y enviarlo a los investigadores desde una dirección de contacto adulta. Los mismos corroborarán esta información y allí liberarán, con un número de acceso, el protocolo para ser completado.

Se alienta a que este protocolo se administre en un marco institucional, donde los responsables serán quienes tomen contacto con los investigadores para agilizar los trámites y también para ofrecer las explicaciones y seguridades del caso.

Estos consentimientos están disponibles por solicitud a enlace mencionado en la web. 
